\title{
Off-Target Effects of Drugs that Disrupt Human Mitochondrial DNA Maintenance
}

\author{
Matthew J. Young* \\ Department of Biochemistry and Molecular Biology, Southern Illinois University School of Medicine, Carbondale, IL, \\ United States
}

OPEN ACCESS

Edited by:

Zvi Kelman,

National Institute of Standards and Technology, United States

Reviewed by:

Kaushlendra Tripathi, University of Alabama at Birmingham, United States

Mahendra Pratap Kashyap, University of Alabama at Birmingham, United States

*Correspondence:

Matthew J. Young matthew.young@siu.edu

Specialty section: This article was submitted to Molecular Diagnostics and Therapeutics,

a section of the journal Frontiers in Molecular Biosciences

Received: 12 September 2017 Accepted: 31 October 2017 Published: 22 November 2017

Citation: Young MJ (2017) Off-Target Effects of Drugs that Disrupt Human Mitochondrial DNA Maintenance.

Front. Mol. Biosci. 4:74. doi: 10.3389/fmolb.2017.00074
Nucleoside reverse transcriptase inhibitors (NRTIs) were the first drugs used to treat human immunodeficiency virus (HIV) the cause of acquired immunodeficiency syndrome. Development of severe mitochondrial toxicity has been well documented in patients infected with HIV and administered NRTIs. In vitro biochemical experiments have demonstrated that the replicative mitochondrial DNA (mtDNA) polymerase gamma, Polg, is a sensitive target for inhibition by metabolically active forms of NRTIs, nucleotide reverse transcriptase inhibitors (NtRTIs). Once incorporated into newly synthesized daughter strands NtRTIs block further DNA polymerization reactions. Human cell culture and animal studies have demonstrated that cell lines and mice exposed to NRTIs display mtDNA depletion. Further complicating NRTI off-target effects on mtDNA maintenance, two additional DNA polymerases, Pol beta and PrimPol, were recently reported to localize to mitochondria as well as the nucleus. Similar to Polg, in vitro work has demonstrated both Pol beta and PrimPol incorporate NtRTIs into nascent DNA. Cell culture and biochemical experiments have also demonstrated that antiviral ribonucleoside drugs developed to treat hepatitis $\mathrm{C}$ infection act as off-target substrates for POLRMT, the mitochondrial RNA polymerase and primase. Accompanying the above-mentioned topics, this review examines: (1) mtDNA maintenance in human health and disease, (2) reports of DNA polymerases theta and zeta (Rev3) localizing to mitochondria, and (3) additional drugs with off-target effects on mitochondrial function. Lastly, mtDNA damage may induce cell death; therefore, the possibility of utilizing compounds that disrupt mtDNA maintenance to kill cancer cells is discussed.

Keywords: nucleoside reverse transcriptase inhibitors, mitochondrial DNA polymerase gamma, human immunodeficiency virus (HIV), mitochondrial diseases, cancer, antiviral ribonucleosides, mitochondrial DNA (mtDNA)

\section{THE ORIGIN OF MITOCHONDRIA AND OFF-TARGET EFFECTS OF ANTIBIOTICS}

Mitochondria are best known for their role in generating energy by oxidative phosphorylation (OXPHOS), the process of coupling substrate oxidation to the production of the energy-rich molecule adenosine triphosphate (ATP). In addition to generating the bulk of the cell's energy supply mitochondria are important sites of calcium homeostasis, nucleotide and amino acid metabolism and biosynthesis of heme, iron-sulfur clusters, and ubiquinone. Mitochondria are 
eukaryotic organelles that share bacterial features such as a double-membrane structure and a circular multi-copied genome or mitochondrial DNA (mtDNA). The endosymbiotic theory hypothesizes mitochondria descended from an ancient alpha $(\alpha)$-proteobacteria that developed a symbiotic relationship with an ancient nucleated cell (Gray, 2017). Support for the endosymbiotic hypothesis comes from striking similarities revealed between the mitochondrial and the Rickettsia prowazekii genomes (Andersson et al., 1998). Over time mitochondria lost most of their proto-bacterial genome to the nucleus. One thousand one hundred and forty-five nuclearencoded mitochondrial gene products must be imported into mitochondria following translation on cytoplasmic ribosomes and estimates place the total mitochondrial proteome at $\sim$ 1,500 gene products (Lopez et al., 2000; Calvo et al., 2016). Currently, there are $\sim 170$ known mitochondrial disease genes associated with $\sim 500$ clinical phenotypes suggesting that most medical specialists could see patients with mitochondrial disease (Scharfe et al., 2009; Turnbull and Rustin, 2016). The $\alpha$-proteobacterial endosymbiont origin of mitochondria is supported by observations that certain antibiotics have off-target effects on mitochondrial ribosomes. Similar to bacterial translation, mitochondrial translation is initiated with an $N$-formylmethionine and mitochondrial but not cytoplasmic translation is sensitive to bacterial antibiotics such as chloramphenicol (CAP) and aminoglycosides (Wallace et al., 1975; Oliver and Wallace, 1982; Wallace and Chalkia, 2013). Additionally, mitochondrial ribosomes are resistant to inhibitors of eukaryotic translation such as emetine and cycloheximide (Oliver and Wallace, 1982).

\section{MITOCHONDRIAL DISORDERS AND THE IMPORTANCE OF mIDNA MAINTENANCE IN HUMAN HEALTH}

The haploid human nuclear genome consists of $\sim 3$ billion base pairs (bp) of DNA and contains $\sim 20,000$ protein-coding genes and $\sim 23,000$ non-coding genes. Examples of non-coding genes include transfer RNA (tRNA), ribosomal RNA (rRNA), micro RNA (miRNA), miscellaneous RNA (miscRNA), small nucleolar RNA (snoRNA), small nuclear RNA (snRNA), small cytoplasmic RNA (scRNA), and long non-coding RNA (lncRNA). In comparison, the mitochondrial genome harbors only 13 genes for polypeptides, 2 genes for rRNA, and 22 genes for tRNA on $\sim 16,600$ bp and mutations associated with maternally-inherited mitochondrial disorders have been identified in all 37 open reading frames. Similar to practically all prokaryotic genes, human mtDNA genes lack introns. The 13 polypeptide-encoded genes code for subunits of the mitochondrial inner membrane (MIM) OXPHOS machinery. While the size and coding capacity of mtDNA is much less than the nuclear genome our maternally inherited genome is critical to cellular viability as exemplified by the numerous disease mutations associated with it and by observations that knocking out mtDNA maintenance genes results in embryonic lethality in various mouse models (Park and Larsson, 2011). Currently, greater than $660 \mathrm{mtDNA}$ mutations are associated with disease phenotypes (www.mitomap.org). The most common encephalopathies caused by mtDNA point mutations include Leigh Syndrome, Leber Hereditary Optic Neuropathy, MERRF (myoclonic epilepsy with ragged red fibers), MIDD (maternally inherited diabetes and deafness), MELAS (mitochondrial encephalomyopathy, lactic acidosis, and stroke-like episodes), non-syndromic hearing loss, and NARP (neuropathy, ataxia, retinitis pigmentosa) (Pinto and Moraes, 2014). Maintenance of the mitochondrial genome is also required to avoid apoptosis induced by mtDNA damage (Santos et al., 2003; Tann et al., 2011).

Molecules of mtDNA associate with various DNA-binding proteins on the matrix-side of the MIM and form proteinmtDNA structures known as nucleoids (Bogenhagen et al., 2008; Brown et al., 2011; Hensen et al., 2014; Young et al., 2015). Utilizing live-cell fluorescence microscopy or immunocytochemistry, nucleoids can be visualized as foci or puncta. Furthermore, a single cell can contain several thousand copies of mtDNA which are distributed within hundreds of individual mitochondria or throughout an elaborate mitochondrial reticular network (Miller et al., 2003; Spelbrink, 2010; Archer, 2013; Young et al., 2015). Localization of mtDNA at the MIM is likely important to coordinate mtDNA replication and transcription with mitochondrial translation, cytoplasmic translation, and mitochondrial protein import and assembly (Iborra et al., 2004; Spelbrink, 2010). Nuclearencoded mitochondrial transcription machinery is imported into the organelle to transcribe mtDNA genes. Nuclear-encoded mitochondrial ribosomal subunits assemble with mtDNAencoded rRNAs following protein import to form the translation machinery necessary to synthesize the $13 \mathrm{mtDNA}$-encoded polypeptides. Therefore, the MIM OXPHOS energy-generating process is strictly dependent on mtDNA maintenance and pharmacological blocks to mitochondrial genome replication would be devastating to this energy-generating process.

\section{MITOCHONDRIAL REACTIVE OXYGEN SPECIES (ROS) AND BASE EXCISION REPAIR (BER)}

Aberrant electron leakage from the OXPHOS machinery to molecular oxygen $\left(\mathrm{O}_{2}\right)$ can generate reactive oxygen species (ROS) which, if not detoxified, cause damage to intracellular molecules such as DNA, RNA, lipids, and proteins (Wallace, 2005). The close proximity of mtDNA-containing nucleoids to the OXPHOS machinery generating ROS has been suggested to inflict more damage on the mitochondrial genome than on the nuclear genome (Tann et al., 2011). ROS-induced DNA damage includes a large quantity of mutagenic oxidized bases and the mutation rate of human mtDNA has been estimated to be 20-100-fold higher relative to nuclear DNA. Nuclearencoded base excision repair (BER) machinery is imported into the mitochondrion to assist with mending abnormal and oxidized base lesions. During mitochondrial short-patch BER, an oxidized base may first be excised by a monofunctional DNA glycosylase such as UNG1 or MUTYH, Figure 1A. DNA glycosylase cleaves 


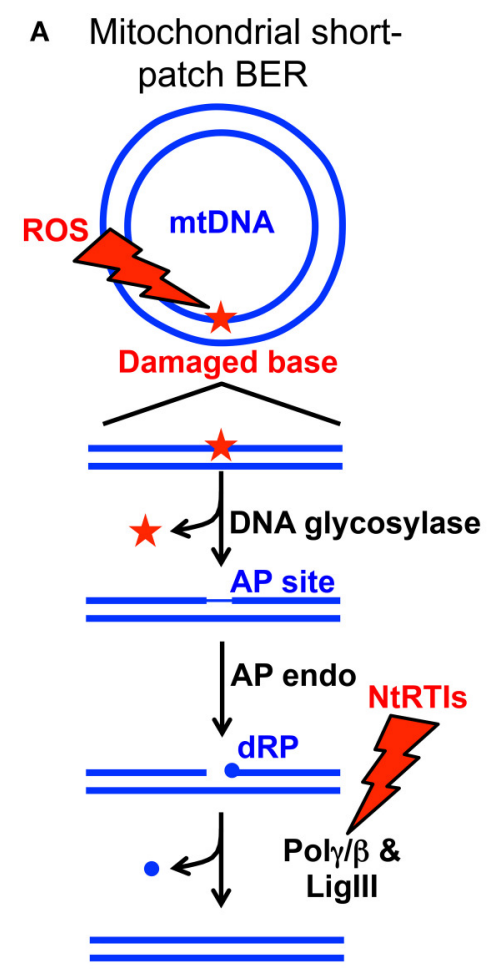

B MtDNA replication

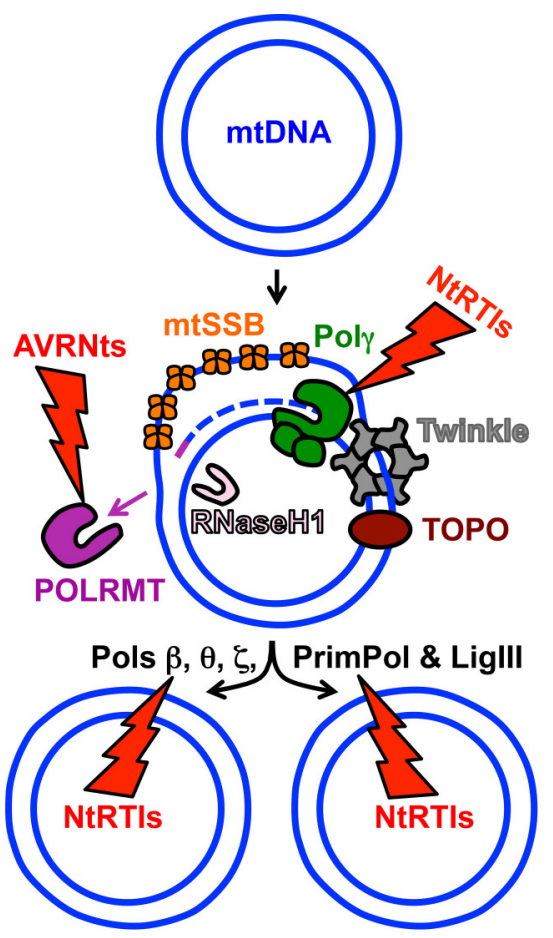

c Mitochondrial TS

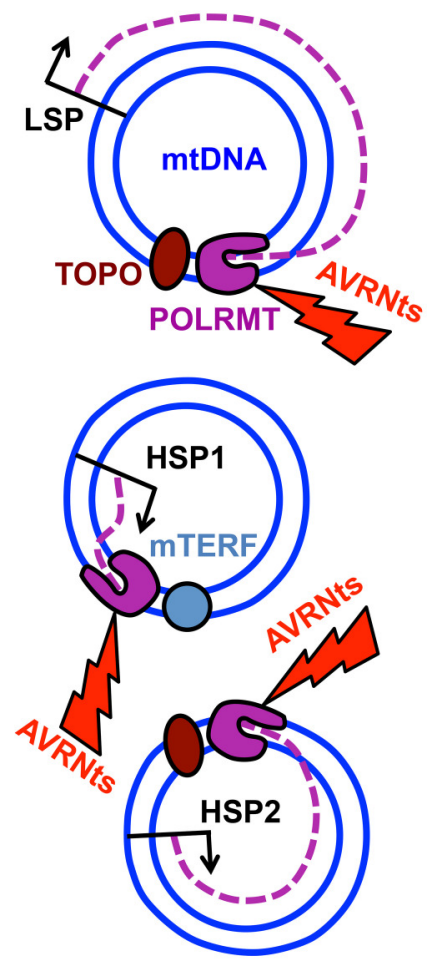

FIGURE 1 | MtDNA maintenance and mitochondrial gene expression. (A) Mitochondrial short-patch base excision repair (BER) initiated with a monofunctional DNA glycosylase. The ROS lightning bolt represents reactive oxygen species-induced mtDNA damage generating an oxidized base lesion (star) that is subsequently removed and repaired by the BER machinery. Two blue circles represent the double-stranded circular mitochondrial genome. A region of the damaged mtDNA is shown below the circular genome to emphasize the BER pathway steps. AP site, apurinic/apyrimidinic site; AP endo, AP endonuclease; dRP, $5^{\prime}$-deoxyribose phosphate; Pol $\gamma / \beta$ the replicative mtDNA polymerase gamma or DNA polymerase beta; Liglll, mitochondrial DNA ligase III. The NtRTIs lightning bolt represents nucleotide reverse transcriptase inhibitors blocking Pol $\gamma$ or $\beta$. (B) Key components of the mtDNA replication and repair machinery. The small purple line represents an RNA primer while the blue dashed line represents newly synthesized mtDNA. TOPO, topoisomerase; Twinkle, Twinkle mtDNA helicase; POLRMT, mitochondrial RNA polymerase and primase; RNaseH1, Ribonuclease $\mathrm{H} 1$; mtSSB, mitochondrial single-stranded DNA binding protein. DNA polymerase beta, theta, zeta, and the DNA primase and translesion DNA polymerase are represented by Pols $\beta, \theta, \zeta$, and PrimPol respectively. These polymerases likely assist Pol $\gamma$ with overcoming mtDNA damage. The AVRNts lightning bolt represents antiviral ribonucleotides blocking POLRMT activity. (C) Polycistronic mitochondrial transcription. Mitochondrial transcription (TS) occurs from three promoters: (1) LSP, light-strand promoter, (2) HSP1, heavy-strand promoter 1, and (3) HSP2, heavy-strand promoter 2. Three purple dashed lines represent transcripts synthesized from the promoters. Although not visualized in the cartoon, mitochondrial TS initiation requires mitochondrial TS factor A (TFAM) and either of mitochondrial TS factors B1 or B2 (TFB1M or TFB2M). It is generally accepted that TFB2M is the primary factor for TS initiation (Shutt et al., 2010). Mitochondrial TS termination factor is represented by mTERF.

the damaged base $N$-glycosidic bond generating an abasic or apurinic/apyrimidinic (AP) site then this site is cleaved by an $\mathrm{AP}$ endonuclease to generate a $3^{\prime}-\mathrm{OH}$ and non-ligatable $5^{\prime}$ deoxyribose phosphate ( $\mathrm{dRP}$ ) moiety. Next, the catalytic subunit of the replicative mitochondrial $5^{\prime}-3^{\prime}$ DNA polymerase gamma $(\operatorname{Pol} \gamma)$ fills in the gap via its DNA polymerase activity and removes the $\mathrm{dRP}$ group via its $5^{\prime}$-deoxyribose phosphate (dRP) lyase activity leaving a $5^{\prime}$-phosphate. Lastly, DNA ligase III seals the nick and the damage is repaired (Longley et al., 1998). Alternatively, a bifunctional DNA glycosylase harboring an intrinsic lyase activity can cleave the $N$-glycosidic bond and incise the AP site; however, the ends generated by the incision are non-ligatable and must be processed by either AP endonuclease or polynucleotide kinase $3^{\prime}$-phosphatase then Pol $\gamma$ can fill the gap and ligase can seal the nick (Bebenek and Kunkel, 2004; Alexeyev et al., 2013). Figure 1A is a simplified cartoon of short-patch BER.
Details regarding mitochondrial short-patch and long-patch BER pathways have been thoroughly reviewed (Alexeyev et al., 2013; Copeland and Longley, 2014; Van Houten et al., 2016).

\section{POL $\gamma$ AND THE REPLISOME}

Human Pol $\gamma$ is the replicative mitochondrial DNA polymerase that harbors $3^{\prime}-5^{\prime}$ exonucleolytic proofreading activity and participates in mtDNA repair (Young and Copeland, 2016). Pol $\gamma$ is a heterotrimer consisting of one $140-\mathrm{kDa}$ catalytic subunit, p140 encoded by the nuclear POLG gene, and a 110$\mathrm{kDa}$ homodimeric processivity subunit, p55 encoded by the nuclear POLG2 gene. MtDNA disorders can be caused by genetic defects in nuclear genes, and a class of genes specifically linked to instability of mtDNA has emerged over the last 
16 years which includes POLG and POLG2, Table 1 (Young and Copeland, 2016). Nuclear mitochondrial disease genes are associated with a complex spectrum of early onset and late onset type phenotypes. One subclass of disorders, mtDNA depletion syndromes, may arise due to defects in genes encoding mtDNA replication machinery (ex. POLG, Alpers-Huttenlocher syndrome) or enzymes required for nucleotide synthesis (ex. TK2). MtDNA depletion syndromes in of themselves are

TABLE 1 | Nuclear genes identified in mitochondrial patients that affect mtDNA stability ${ }^{\mathrm{a}}$.

\begin{tabular}{|c|c|c|c|}
\hline Gene & Disorderb & $\begin{array}{l}\text { Chromosomal } \\
\text { locus }\end{array}$ & Function \\
\hline \multicolumn{4}{|c|}{ MtDNA REPLICATION AND REPAIR } \\
\hline$P O L G$ & PEO/Alpers/ataxia & $15 q 25$ & Pol $\gamma$ catalytic subunit \\
\hline POLG2 & PEO & $17 q$ & Poly processivity subunit \\
\hline Twinkle & PEO/ataxia & $10 q 24$ & MtDNA helicase \\
\hline RNASEH1 & PEO/ataxia & $2 \mathrm{p} 25$ & $\begin{array}{l}\text { Mitochondrial and nuclear } \\
\text { RNaseH1 (Reyes et al., } \\
\text { 2015) }\end{array}$ \\
\hline DNA2 & PEO & 10q21.3-22.1 & $\begin{array}{l}\text { Mitochondrial and nuclear } \\
\text { helicase/nuclease (Ronchi } \\
\text { et al., 2013) }\end{array}$ \\
\hline MGME1 & $\begin{array}{l}\text { PEO, mtDNA } \\
\text { depletion }\end{array}$ & $20 p 11.23$ & RecB type exonuclease \\
\hline TFAM & $\begin{array}{l}\text { Neonatal liver } \\
\text { failure mtDNA } \\
\text { depletion }\end{array}$ & $10 q 21.1$ & $\begin{array}{l}\text { Mitochondrial transcription } \\
\text { factor A (Stiles et al., 2016) }\end{array}$ \\
\hline \multicolumn{4}{|c|}{ MAINTAINING dNTP POOLS } \\
\hline ANT1 & PEO & $4 q 35$ & $\begin{array}{l}\text { Adenine nucleotide } \\
\text { translocator }\end{array}$ \\
\hline$T P$ & MNGIE & $22 q 13.33$ & Thymidine phosphorylase \\
\hline DGUOK & MtDNA depletion & $2 \mathrm{p} 13$ & Deoxyguanosine kinase \\
\hline TK2 & MtDNA depletion & $16 q 22-23.1$ & $\begin{array}{l}\text { Mitochondrial thymidine } \\
\text { kinase }\end{array}$ \\
\hline SUCLA2 & MtDNA depletion & $13 q 14.2$ & $\begin{array}{l}\text { ATP-dependent } \\
\text { Succinate-CoA ligase }\end{array}$ \\
\hline SUCLG1 & MtDNA depletion & $2 \mathrm{p} 11.2$ & $\begin{array}{l}\text { GTP-dependent Succinate } \\
\text { CoA ligase }\end{array}$ \\
\hline RRM2B & MtDNA depletion & $8 q 23.1$ & $\begin{array}{l}\text { p53-Ribonucleotide } \\
\text { reductase, small subunit }\end{array}$ \\
\hline MPV17 & $\begin{array}{l}\text { MtDNA depletion } \\
\text { and deletion }\end{array}$ & $2 \mathrm{p} 23.3$ & $\begin{array}{l}\text { Mitochondrial inner } \\
\text { membrane protein }\end{array}$ \\
\hline ABAT & MtDNA depletion & 16p13.2 & $\begin{array}{l}\text { 4-aminobutyrate } \\
\text { aminotransferase (Besse } \\
\text { et al., 2015) }\end{array}$ \\
\hline
\end{tabular}

MITOCHONDRIAL HOMEOSTASIS AND DYNAMICS

$\begin{array}{llll}\text { OPA1 } & \begin{array}{l}\text { Dominant optic } \\ \text { atrophy }\end{array} & 3 q 29 & \text { Dynamin-related GTPase } \\ \text { MFN2 } & \begin{array}{l}\text { Recessive optic } \\ \text { atrophy }\end{array} & 1 \mathrm{p} 36.22 & \begin{array}{l}\text { Mitofusin 2 (Rouzier et al., } \\ \text { 2012) }\end{array} \\ \text { FBXL4 } & \begin{array}{l}\text { MtDNA depletion, } \\ \text { Encephalopathy }\end{array} & & \begin{array}{l}\text { Mitochondrial LLR F-Box } \\ \text { protein }\end{array}\end{array}$

a The table is an updated version of Table 1 found in reference (Young and Copeland, 2016) and is reproduced with permission.

${ }^{b}$ PEO, progressive external ophthalmoplegia; MNGIE, mitochondrial neurogastrointestinal encephalomyopathy. variable and clinical manifestations may include myopathy, encephalomyopathy, neurogastrointestinal, or hepatocerebral phenotypes (Stiles et al., 2016). In addition to the $5^{\prime}-3^{\prime}$ DNA polymerase, $3^{\prime}-5^{\prime}$ exonuclease, and $5^{\prime} \mathrm{dRP}$ lyase activities mentioned above the p140 catalytic subunit harbors reverse transcriptase (RT) activity (Murakami et al., 2003; Kaguni, 2004; Graziewicz et al., 2006). The RT activity or RNA-dependent DNA polymerase activity is similar to viral enzymes such as human immunodeficiency virus RT (HIV-RT). Unfortunately, as will be discussed below, biochemical experiments have demonstrated that Pol $\gamma$ is sensitive to inhibition by metabolically active forms of anti-HIV nucleoside reverse transcriptase inhibitors (NRTIs) known as nucleotide reverse transcriptase inhibitors (NtRTIs). Treatment of HIV-infected patients with NRTIs is accompanied by loss of mitochondrial function and NRTI toxicity mimics mitochondrial genetic diseases and induces similar symptoms such as mtDNA depletion (Graziewicz et al., 2006). One explanation as to why Pol $\gamma$ harbors RT activity may be to replicate past ribonucleotides (ribonucleoside monophosphates) that are evenly distributed between the two strands of mtDNA (Murakami et al., 2003; Berglund et al., 2017). The homodimeric Pol $\gamma$ p55 subunit imparts high processivity onto the holoenzyme by increasing the binding affinity to DNA (Lim et al., 1999; Young et al., 2015). Processivity is a measurement of the extent of Pol $\gamma$ DNA synthesis during a primer-template binding event. Pol $\gamma$ functions in conjunction with several replisome components including: (1) topoisomerase, (2) mitochondrial single-stranded DNA binding protein (mtSSB), (3) Twinkle mtDNA helicase, (4) RNaseH1, (5) mitochondrial RNA polymerase (POLRMT), and (6) mitochondrial DNA ligase III, Figure 1B. Additional factors critical for mitochondrial genome maintenance include: the multifunctional mitochondrial transcription factor A (TFAM) with significant roles in mtDNA replication and packaging, the RecB-type mitochondrial genome maintenance $5^{\prime}-3^{\prime}$ exonuclease 1 (MGME1), the RNA and DNA $5^{\prime}$ flap endonuclease (FEN1), and the helicase/nuclease, DNA2 (Kalifa et al., 2009; Kornblum et al., 2013; Ngo et al., 2014). MGME1, FEN1, and DNA2 have all been implicated in mtDNA BER (Copeland and Longley, 2014). Furthermore, DNA2 has been shown to stimulate Pol $\gamma$ activity and to co-localize with Twinkle in the mitochondrial nucleoid, which suggests an important role in the replisome (Zheng et al., 2008). Some of the genes encoding components of the mtDNA replication machinery may have been acquired as part of a protomitochondrial genome, in the form of integrated phage genes from a T-odd lineage, which were then transferred to the eukaryotic nucleus (Shutt and Gray, 2006). This hypothesis is based on the shared conservation of primary protein amino acid sequences of T-odd bacteriophages with mitochondrial Pol $\gamma$, POLRMT, and Twinkle helicase.

In agreement with the requirement for mtDNA replication re-initiation between embryonic day (E)6 and 7.5 (Stewart and Larsson, 2014), p140 in animal cells was shown to be essential using POLG knockout (KO) mice. The POLG KO results revealed embryonic lethality at E7.5-8.5 with subsequent depletion of mtDNA (Hance et al., 2005). Comparatively, several studies have illustrated the essential role of p55 in mtDNA replication: (i) two separate null mutations in the Drosophila melanogaster 
POLG2 gene lead to lethality in the early pupal stage of fly development (Iyengar et al., 2002), (ii) homozygous POLG2 KO mice are embryonic lethal at E8-8.5 (Humble et al., 2013), and (iii) in a porcine oocyte knockdown model, oocyte maturation requires POLG2 (Lee et al., 2015). Mouse $\mathrm{RNaseH}^{-/-}$embryos are null at E8.5 and have decreased mtDNA content leading to apoptotic cell death (Cerritelli et al., 2003). A mouse model of Twinkle deficiency has been generated by transgenic expression of a Twinkle cDNA with an autosomal dominant mutation found in patients (Tyynismaa et al., 2005; Tyynismaa and Suomalainen, 2009). These mice developed progressive respiratory chain deficiency at 1 year of age in cerebellar Purkinje cells, hippocampal neurons, and skeletal muscle. The affected cells accumulated multiple mtDNA deletions. These "Deletor" mice recapitulate many of the symptoms associated with PEO and represent a useful research model.

\section{NEWLY IDENTIFIED HUMAN DNA POLYMERASES LOCALIZING TO MITOCHONDRIA - POLS $\beta, \theta, \zeta$, AND PRIMPOL}

Prior to 2013 human Pol $\gamma$ was the only polymerase out of the 17 known cellular DNA polymerases demonstrated to localize to human cell mitochondria; however, mounting evidence suggests it is not the only one. Recently, DNA polymerase beta $(\mathrm{Pol} \beta)$ was detected in mitochondrial extracts prepared from human embryonic kidney cells (HEK-293T) and from various tissues obtained from mice (Sykora et al., 2017). Analysis of mouse tissue extracts revealed $\operatorname{Pol} \beta$ in brain and kidney mitochondria while none was detectable in heart, liver, or muscle. As a key member of the nuclear BER machinery Pol $\beta$ provides the majority of the required $5^{\prime}$-dRP lyase activity in the nucleus; therefore, $\operatorname{Pol} \beta$ may participate in mitochondrial BER. In a short-patch BER scenario, following the actions of a monofunctional DNA glycosylase and an AP endonuclease Pol $\beta$ could insert a nucleotide onto the $3^{\prime}-\mathrm{OH}$ then remove the $5^{\prime}$ dRP group using its dRP lyase activity followed by the nick sealing action of DNA ligase (Figure 1A). As mentioned above mitochondrial ribosomes are sensitive to CAP $\left(\mathrm{CAP}^{\mathrm{S}}\right)$. MtDNA can develop resistance to $\mathrm{CAP}\left(\mathrm{CAP}^{\mathrm{R}}\right)$ through mutation of the mtDNA 16S rRNA gene changing the specificity of CAP for the mitochondrial ribosome and inhibiting its binding (Blanc et al., 1981; Kearsey and Craig, 1981; Wallace and Chalkia, 2013; Sykora et al., 2017). In two HEK-293T Polß KO cell lines very few $C A P^{R}$ cells could be isolated relative to the parental cell line when plated at high cell density. This finding suggests that $\operatorname{Pol} \beta$ may mediate mtDNA mutational events. Utilizing in vitro biochemistry $\operatorname{Pol} \beta$ was also demonstrated to interact with the mitochondrial Twinkle helicase and this interaction facilitated Pol $\beta$ strand displacement. Enhanced strand displacement suggests $\operatorname{Pol} \beta$ may participate in the mitochondrial long-patch BER pathway (Sykora et al., 2017). As many Twinkle gene-disease mutations result in protein variants with partial helicase defects (Longley et al., 2010) it would be interesting to investigate strand displacement using recombinant Twinkle disease variants and $\mathrm{Pol} \beta$ to provide insight into possible mechanisms of Twinkle-related mitochondrial disease. Besides BER, other roles of Pol $\beta$ in mtDNA maintenance remain to be elucidated. Pol $\beta$ is not likely a replicative mtDNA polymerase as this enzyme lacks $3^{\prime}-5^{\prime}$ exonuclease proofreading activity, has low processivity, incorporating few nucleotides each time it binds a primer-template, and has a high error rate relative to the proofreading proficient Pol $\gamma$ (Bebenek and Kunkel, 2004). However, POLG-related disease mutations that abolish p140 activity and are associated with late age of onset may argue in favor of redundant DNA polymerase function(s) in human cell mitochondria (Sykora et al., 2017). Pol $\beta^{-/-}$mouse embryos survive the course of development but die immediately at the perinatal stage suggesting the cause of death is a neonatal respiratory defect (Sugo et al., 2000).

The DNA primase and translesion DNA polymerase, PrimPol, has been identified in mitochondria isolated from HEK-293T cells (García-Gómez et al., 2013). Translesion DNA polymerases are specialized enzymes that pass through DNA damage. However, PrimPol is likely only required for mtDNA repair and not for mtDNA replication, as PRIMPOL ${ }^{-/-} \mathrm{KO}$ mice are viable. Like Pol $\beta$ PrimPol is localized to both the nucleus and the mitochondrion and lacks proofreading activity. Of note to human genetic disease, mutation of PRIMPOL is associated with the ocular disorder high myopia (Zhao et al., 2013; Keen et al., 2014). DNA polymerase theta $(\operatorname{Pol} \theta)$ was recently identified in mitochondria isolated from human cells (Wisnovsky et al., 2016). $\operatorname{Pol} \theta$ is a proofreading-deficient and error-prone polymerase capable of translesion DNA polymerization (Arana et al., 2008). In the nucleus, Pol $\theta$ is implicated in double-strand DNA break repair, non-homologous end joining and maintenance of DNA replication timing. The translesion DNA polymerase zeta (Polל) is composed of two subunits the catalytic subunit Rev 3 and the structural subunit Rev7. To date, no evidence for Rev7 localization to human cell mitochondria has been described but the Rev3 subunit has been reported to localize to the organelle and may play a role in protecting mtDNA from ultraviolet radiation-induced DNA damage (Singh et al., 2015). Compared to Pol $\gamma$, Pols $\theta$ and $\zeta$ localize to both the nucleus and the mitochondrion, have low fidelity, lack proofreading activity and have only moderate processivity (Bebenek and Kunkel, 2004; Arana et al., 2008; Lee et al., 2014); therefore, their main roles are likely in assisting the core replisome in overcoming mtDNA damage. Pol$\theta \mathrm{KO}$ mice are viable whereas Polל KO mice are embryonic lethal with a block in embryo development not beyond $8-8.5$ days post-coitus (Esposito et al., 2000; Shima et al., 2004). Details regarding the evidence supporting mitochondrial localization of the aforementioned human DNA polymerases have been reviewed (Krasich and Copeland, 2017).

\section{NUCLEOSIDE REVERSE TRANSCRIPTASE INHIBITORS, NRTIS}

NRTIs were the first drugs used to treat HIV, the cause of acquired immunodeficiency syndrome (AIDS). NRTIs remain effective today for treating HIV when combined with other drugs. Highly active antiretroviral therapy (HAART) uses multiple drugs to act on different HIV life-cycle stages. For patients 
with HIV infection, HAART regimens include treatment with NRTIs in combination with non-nucleoside reverse transcriptase inhibitors (NNRTIs) or protease inhibitors, PIs (Nolan and Mallal, 2004). NNRTIs and NRTIs primarily block HIV genome replication by inhibiting the HIV-RT from transcribing the viral single-stranded RNA genome into DNA. FDA-approved NRTIs used to treat HIV infection include: ddC (zalcitabine), 3TC (Epivir ${ }^{\circledR}$, lamivudine), AZT (Retrovir ${ }^{\circledR}$, zidovudine), ddI (Videx-EC ${ }^{\circledR}$, didanosine), PMPA (Viread ${ }^{\circledR}$, tenofovir DF), d4T (Zerit ${ }^{\circledR}$, stavudine), ABC (Ziagen ${ }^{\circledR}$, abacavir), and FTC (emtricitabine, Emtriva ${ }^{\circledR}$ ), Table 2. NRTIs may be administered to patients in fixed-dose combinations: Combivir ${ }^{\circledR}$ (Retrovir + Epivir), Descovy ${ }^{\circledR}$ (tenofovir alafenamide + Emtriva), Epzicom ${ }^{\circledR}$ (Epivir + Ziagen), Trizivir ${ }^{\circledR}$ (Retrovir + Epivir + Ziagen), and Truvada ${ }^{\circledR}$ (Viread + Emtriva), https://www. hiv.va.gov/patient/treat/NRTIs.asp. The history of antiretroviral drugs and the currently used antiretroviral therapies have been reviewed (Pau and George, 2014). A discussion of what is currently known regarding NRTIs with off-target effects on mtDNA replication is discussed below.

Nucleoside analogs, including NRTIs, are taken up by cells then phosphorylated to active nucleotide analogs by intracellular kinases (Zhu et al., 2000). Nucleoside kinases such as DCK, CMPK1, and nucleoside diphosphate kinases (NME) act on NRTIs like ddC and perform the first, second, and third phosphorylation steps respectively generating the active NtRTI in the cytoplasm ex. ddCppp, where ppp represent the triphosphate (Liyanage et al., 2017). NtRTIs can then be imported into mitochondria and could compete with native nucleotides at DNA polymerase active sites to inhibit mtDNA replication through chain termination and persistence in the mitochondrial genome. Unlike natural deoxyribonucleotide triphosphate substrates, and with the exception of FIAU, NtRTIs are chain terminators that lack the $3^{\prime}$ hydroxyl group and therefore cannot be extended by a polymerase once incorporated into DNA. Therefore, if these analogs are not removed from DNA, replication will stall (Figure 1B).

\section{CLINICAL EVIDENCE FOR NRTI DISRUPTION OF mIDNA REPLICATION}

In clinical trials drugs that showed promise in AIDS therapy, such as fluoro-dideoxyadenosine (FDDA), or in the treatment of chronic hepatitis B infection, such as FIAU, toxicity was reported affecting peripheral nerves, liver, skeletal, and cardiac muscle (Lewis et al., 2001). Toxicity to mitochondria was so severe that hepatic failure and death in some patients necessitated discontinuation of their use (McKenzie et al., 1995). One longterm AZT use study of HIV-positive patients concluded that AZT treatment caused toxic mitochondrial myopathy (Dalakas et al., 1990). In a follow-up study investigating mtDNA content in muscle biopsies, mitochondrial genome depletion was discovered in all HIV-positive patients who were treated with AZT and who displayed myopathy and ragged-red fibers in comparison to controls (Arnaudo et al., 1991). Another study investigated HIV-positive patients who developed neuropathy 6-10 weeks after starting $\mathrm{ddC}$ and this investigation found mitochondrial alterations and significantly reduced mtDNA copy number in nerve biopsy specimens (Dalakas et al., 2001). These and other observations led to the Pol $\gamma$ dysfunction hypothesis. Hypothetically, poisoning of Pol $\gamma$ would lead to decreased mtDNA, increased mitochondrial stress due to compromised OXPHOS (as OXPHOS subunits are encoded by mtDNA), increased cellular energy depletion (due to diminished ATP pools), and acquired mitochondrial disease phenotypes (Koczor and Lewis, 2010). Key side effects of NRTIs are summarized in Table 2 and (Koczor and Lewis, 2010). Support for the Pol $\gamma$ dysfunction hypothesis comes from cell culture and biochemical work discussed below.

\section{EVIDENCE FOR POL $\gamma$-MEDIATED NRTI TOXICITY FROM BIOCHEMICAL STUDIES}

Pol $\gamma$-mediated NRTI mitochondrial toxicity requires that analogs be metabolized to NtRTIs, imported into mitochondria then incorporated into mtDNA and persist there to block further genome replication events. Support for NRTI toxicity caused by inhibition of Pol $\gamma$ DNA polymerase activity comes from extensive biochemical evidence. Pre-steady and steadystate enzyme kinetic analyses have demonstrated that Pol $\gamma$ is able to incorporate various anti-retroviral NtRTIs (Martin et al., 1994; Johnson et al., 2001; Lim and Copeland, 2001; Brown et al., 2011). NtRTIs that have been tested in vitro for incorporation into nascent DNA by Pol $\gamma$ include: ddCppp, ddTppp, d4Tppp, ddAppp (the active form of ddI), (+) and (-)3TCppp, PMPApp (PMPA triphosphate), AZTppp, CBVppp (the active form of $\mathrm{ABC}$ ), and FIAUppp. These biochemical studies agree that Pol $\gamma$ incorporates NtRTIs during DNA replication; however, the efficiency of analog incorporation is variable among the NtRTIs that have been examined. Pol $\gamma$ incorporates ddCppp, ddAppp (ddI), and d4Tppp analogs most efficiently while 3TCppp, PMPApp, AZTppp, and CBVppp $(\mathrm{ABC})$ are modestly incorporated into DNA. Steady-state and pre-steady-state kinetics have also demonstrated that FIAUppp is strongly incorporated by Pol $\gamma$ (Lewis et al., 1996; Johnson et al., 2001). Mitochondrial toxicity, therefore, may be acquired due to a block in mtDNA replication if chain-terminating NtRTIs cannot be removed. Indeed, biochemical evidence has shown that Pol $\gamma$ does not efficiently proofread NtRTIs incorporated into DNA. Pre-steady-state measurements have demonstrated that a ddCp (ddC monophosphate) incorporated into the $3^{\prime}$-end of a DNA oligonucleotide annealed to a DNA template essentially cannot be removed by Pol $\gamma$ proofreading activity even after 12$\mathrm{h}$ incubations with the DNA duplex (Johnson et al., 2001). The remaining NtRTIs analyzed for exonucleolytic removal had slow rates of excision and it has been estimated that the half-life of the reaction to remove $(+) 3 \mathrm{TCp}$ or $(-) 3 \mathrm{TCp}$ is $\sim 1 \mathrm{~min}$ (Feng et al., 2001). The rate of NtRTI excision could be detrimental in vivo by slowing the mtDNA replication machinery. If Pol $\gamma$ dissociates from mtDNA prior to cleaving an incorporated nucleotide analog then replication would be terminated. When PMPA-terminated DNA substrate was tested for excision in the presence of trap 


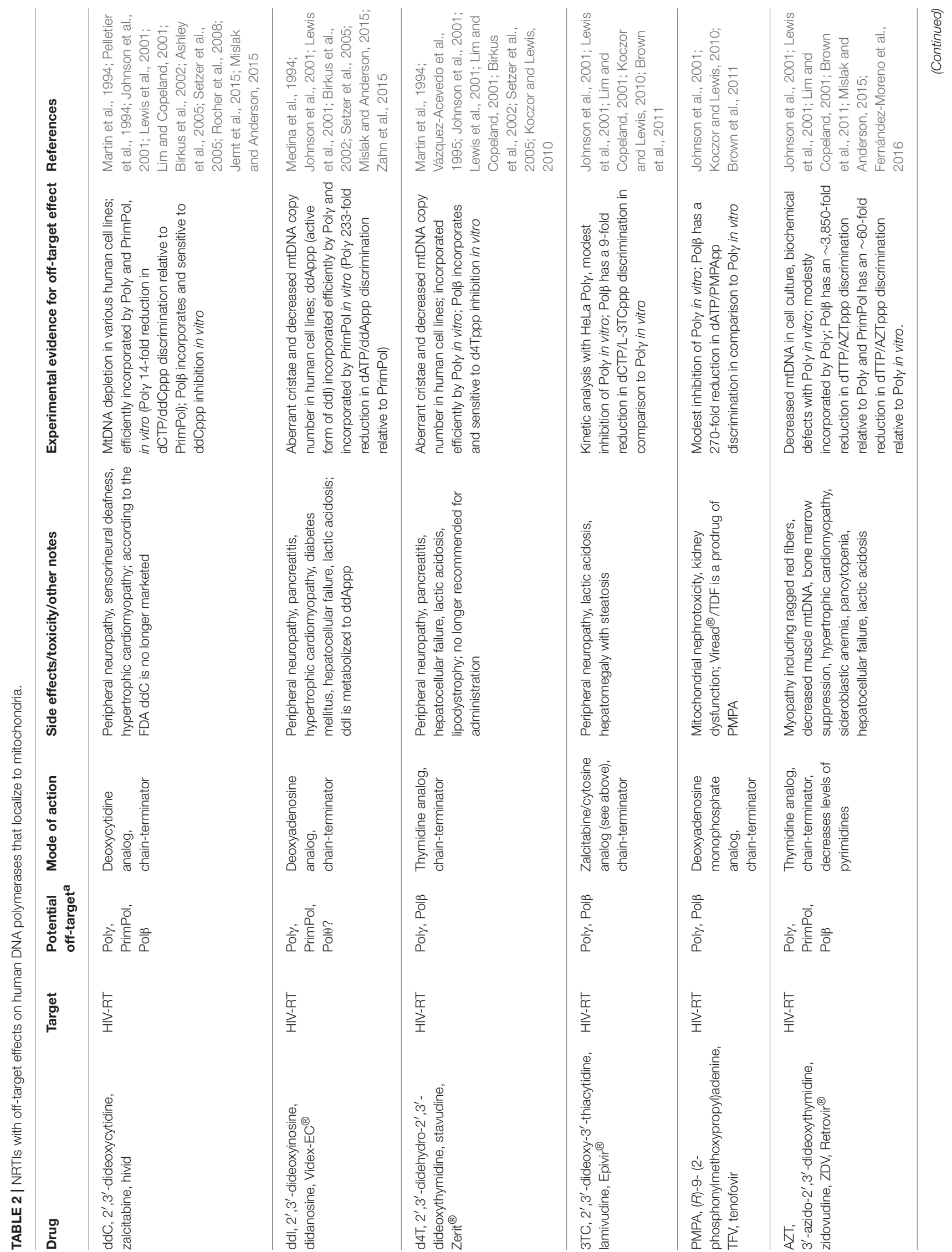




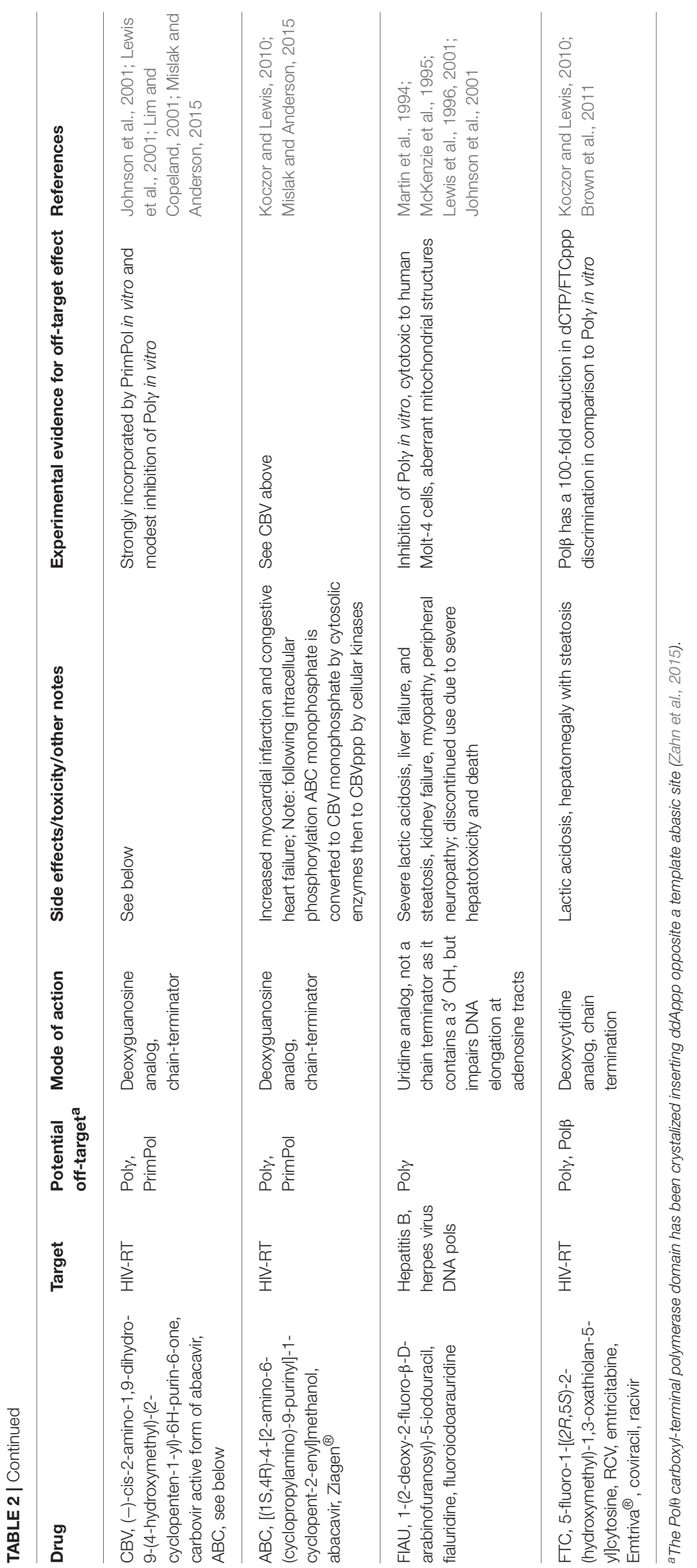


DNA, no Pol $\gamma$ exonuclease activity was detected (Johnson et al., 2001). This finding suggests that NtRTI-containing duplex DNA is released from Pol $\gamma$ prior to NtRTI excision and perhaps a similar mechanism could happen in vivo with many copies of mtDNA. Similar findings of slow rates of NtRTI excision were observed utilizing steady-state analyses. Additionally, Pol $\gamma$ exonuclease activity was inhibited at in vivo concentrations of the AZTppp phosphorylated intermediate AZT monophosphate, AZTp (Lim and Copeland, 2001). Perhaps in vivo intracellular levels of AZTp allow for binding of the analog to the exonuclease active site and lower Poly's fidelity by blocking proofreading.

In 2015 crystal structures of Pol $\gamma$-DNA replication complexes separately bound to ddCppp or to the natural substrate dCTP were solved (Szymanski et al., 2015). Within the DNA polymerase active site the side chain of the p140 Y951 residue stacks with the incoming ddCppp nearly identically to the natural dCTP substrate. The ribose sugar moieties of both nucleotides are located $3.5 \AA$ from the p140 Y951 hydroxyl group. In support of the p140 Y951 residue being the likely cause of ddCppp toxicity, a biochemical study demonstrated that mutation of Y951 to phenylalanine maintains DNA polymerase activity but renders p140 Y951F almost completely incapable of incorporating ddCppp, CBVppp, 3TCppp, and d4Tppp (Lim et al., 2003). The p140 Y951F had a 2,400-fold increase in dCTP/ddCppp discrimination relative to wild-type p140. Therefore, the substitution of the smaller phenylalanine side chain in the 140 Y951F variant must influence the structure such that ddCppp is excluded from the DNA polymerase active site and not readily incorporated into DNA.

Variability in mtDNA depletion has been observed in HIVpositive patients treated with NRTIs and may result from a difference in treatment times or from genetic variations that have increased susceptibility to NRTIs or both. A homozygous mutation encoding p140 R964C was identified in a 34-year-old HIV-infected woman with a history of lactic acidosis induced by d4T treatment (Yamanaka et al., 2007). Recombinant p140 R964C displays 14\% polymerase activity relative to WT p140. Additionally, a patient-derived p140 R964C lymphoblastoid cell line (LCL) cultured with $\mathrm{d} 4 \mathrm{~T}$ displays mtDNA depletion relative to a WT LCL suggesting p140 R964C is associated with severe lactic acidosis induced by NRTI use. A pre-steady state analysis of Pol $\gamma$ holoenzyme harboring the p140 R964C variant determined that the substitution caused a $33 \%$ reduction in dTTP incorporation efficiency and a 3-fold decrease in $\mathrm{dTTP} / \mathrm{d} 4 \mathrm{Tppp}$ discrimination relative to WT suggesting p140 R964C has a higher propensity to incorporate d4Tppp (Bailey et al., 2009). The p140 R964 residue is located in close proximity to the DNA polymerase active site. One explanation for the mechanism of increased $\mathrm{d} 4 \mathrm{Tppp}$ incorporation is that the p140 R964C substitution modulates active site access increasing binding to d4Tppp. Also, a heterozygous mutation $(\mathrm{C}>\mathrm{T}$ 2857/p140 R953C) was identified in an HIV-infected patient undergoing antiretroviral therapy who displayed mitochondrial toxicity and mtDNA depletion (Li et al., 2016). The recombinant R953C Pol $\gamma$ holoenzyme displayed an 8-fold weakened ability to bind to dCTP and a 4 -fold decrease in its ability to discriminate between $\mathrm{dCTP}$ and (-)-3TCppp relative to WT.
Molecular modeling revealed that a cysteine substitution at position 953 in p140 could abolish interactions between p140 side chain residues in the active site thereby reducing the binding of an incoming nucleotide. In another case-control study examining the relationship between p140 E1143D/G substitutions, lipodystrophy, and $\mathrm{d} 4 \mathrm{~T}$ treatment it was concluded that HIV-infected patients harboring an E1143D/G variant are 4fold more likely to develop lipodystrophy and if treated with $\mathrm{d} 4 \mathrm{~T}$ the risk of developing lipodystrophy increased (Chiappini et al., 2009).

\section{EVIDENCE FOR NRTI DISRUPTION OF MIDNA REPLICATION FROM CELL CULTURE AND ANIMAL STUDIES}

Support for intracellular NRTI mitochondria toxicity mediated by disruption of mtDNA replication comes from observations that primary and immortalized cell lines undergo mtDNA depletion upon exposure to various NRTIs. Table 3 lists examples of human cell lines exposed to various nucleoside analogs in tissue culture. In some reports, mtDNA depletion was so severe cell lines became rho zero completely lacking mtDNA. These findings are similar to what has been reported with LA9 mouse cells exposed to ddC (Brown and Clayton, 2002) and with treating human cell lines with the mtDNA replication inhibitor ethidium bromide, EtBr (King and Attardi, 1996). Low concentrations of EtBr either partially or completely inhibit maintenance of the negatively supercoiled circular mitochondrial genome but not nuclear DNA (nDNA). EtBr binds better to negatively supercoiled substrates than to positively supercoiled ones and might enhances topoisomerase-mediated cleavage of negatively supercoiled DNA; therefore, EtBr may act as a topoisomerase topological poison (Gentry et al., 2011). In agreement with Pol $\gamma$ biochemical analyses, treatment of human cell lines with several nucleoside analogs typically duplicate the finding that $\mathrm{ddC}$ causes the most severe inhibition of mtDNA replication as indicated by mtDNA depletion. In an animal study investigating AZT exposure by administering the drug in drinking water to rats, transmission electron microscopy revealed widespread mitochondrial alterations in the heart following 35 days of treatment with $1 \mathrm{mg} / \mathrm{ml} \mathrm{AZT} \mathrm{(Lewis} \mathrm{et} \mathrm{al.,} \mathrm{1991).} \mathrm{In} \mathrm{another} \mathrm{4-}$ month study investigating the treatment of BALB/C mice with ddI, d4T, AZT, or 3TC, and with the exception of liver tissue from mice treated with $3 \mathrm{TC}$, mtDNA depletion was reported in liver, muscle, and cortical neurons. Also, cortical neurons isolated from mice treated with ddI, d4T, and 3TC were reported to harbor an increased level of mtDNA deletions (Zhang Y. et al., 2014).

\section{OTHER POTENTIAL MECHANISMS OF NRTI TOXICITY}

Other mechanisms of NRTI toxicity include increased frequency of mtDNA mutations (perhaps from an altered Pol $\gamma$ function), enhanced oxidative stress, and competition with endogenous nucleotides for kinases required to phosphorylate and activate them thereby lowering the in vivo concentrations of nucleotides 
TABLE 3 | NRTIs that disrupt mtDNA maintenance in human cell lines.

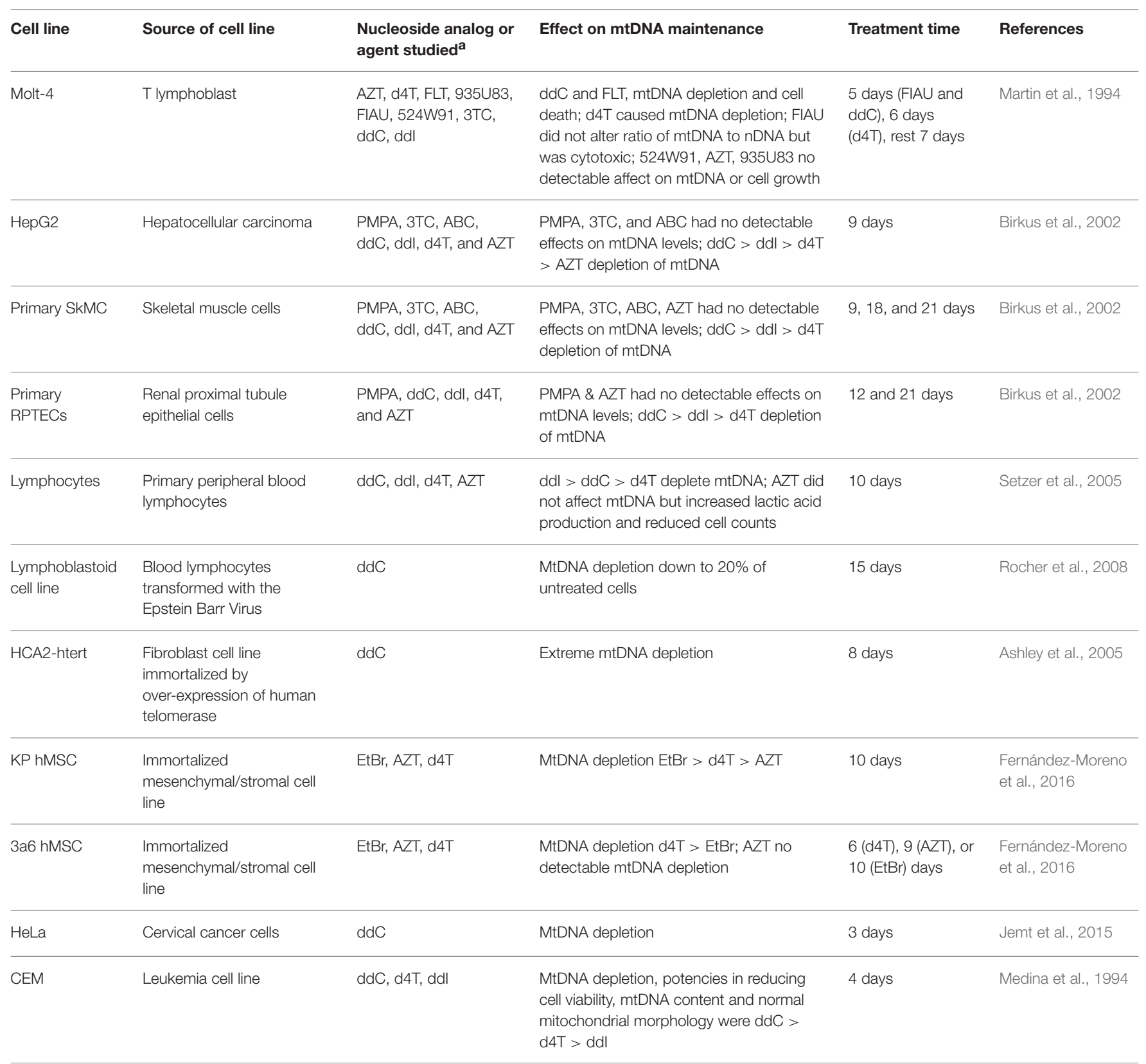

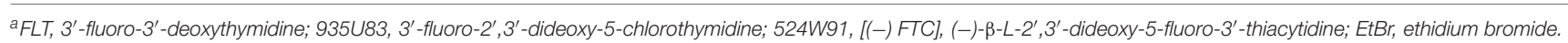

available to replicate mtDNA (McKee et al., 2004). The recent discovery of other cellular DNA polymerases localizing to human mitochondria also has implications for NRTI toxicity as these enzymes may incorporate analogs. Purified $\operatorname{Pol} \beta$ is considerably sensitive to NtRTIs including d4Tppp and ddCppp (Martin et al., 1994; Pelletier et al., 1994) and compared to Pol $\gamma$ is less selective for and can incorporate AZTppp, PMPApp, LFTCppp, and L-3TCppp (Table 2 and Brown et al., 2011). In the nucleus Pols alpha $(\alpha)$, delta $(\delta)$, and epsilon $(\varepsilon)$ harbor strong nucleotide selection mechanisms and are less likely to incorporate NtRTIs (Brown et al., 2012). Incorporation of
NtRTIs by Pol $\beta$ within the organelle would be complicated by (1) the sensitivity of analog incorporation by Pol $\gamma$ and (2) the lack of Pol $\beta$ proofreading activity, which would likely contribute to NtRTI persistence within mtDNA. Figures 1A,B highlight key steps in BER and mtDNA replication that could be negatively affected by NtRTIs. Finally, the mitochondrial localization of DNA repair polymerases with flexible active sites could allow for accommodation of nucleotide analogs and contribute to unwanted insertion of chain terminators. Pre-steady-state analyses of PrimPol NtRTI incorporation kinetics revealed effective incorporation of CBVppp, followed 
by ddCppp > ddAppp > AZTppp while d4Tppp, 3TCppp, PMPApp, and FTCppp were not readily incorporated. From this study, it was determined that CBVppp is actually a better substrate for PrimPol than for HIV-RT which may help to explain life-threatening sensitivity to this analog in some patients (Mislak and Anderson, 2015).

\section{EVIDENCE FOR POLRMT-MEDIATED AVRN TOXICITY FROM BIOCHEMICAL AND CELL CULTURE STUDIES}

POLRMT directs polycistronic transcription from three promoters the heavy-strand promoter 1 (HSP1), the HSP2, and the light-strand promoter, LSP (Lodeiro et al., 2012; Figure 1C). The two mtDNA strands are named heavy $(\mathrm{H})$ and light $(\mathrm{L})$ based on the ability to separate them on alkaline cesium chloride buoyant density gradients (Kasamatsu and Vinograd, 1974). RNA polymerase enzymes known as primases synthesize RNA primers required for initiation of DNA replication. Evidence supporting the role of human POLRMT as the mtDNA primase comes from the identification of primers located adjacent to nascent $\mathrm{H}$ strands isolated from human KB cell mitochondria (Chang and Clayton, 1985), from in vitro experiments demonstrating that POLRMT has primase activity (Wanrooij et al., 2008), and from the observation that replicating mtDNA obtained from mouse embryonic fibroblasts, and lacking RNaseH1, retain unprocessed primers at origins of replication (Holmes et al., 2015). The $5^{\prime}$-end of RNA primers that have been mapped to the LSP therefore likely serve to initiate synthesis of nascent $\mathrm{H}$-strand mtDNA (Chang and Clayton, 1985; Figure 1B). Consequently, mtDNA replication is likely dependent on mitochondrial transcription.

Sofosbuvir is an antiviral uridine analog inhibitor of hepatitis $\mathrm{C}$ virus (HCV) RNA-dependent RNA polymerase (HCV nonstructural protein $5 \mathrm{~B}$, NS5B) currently approved for use to treat patients with $\mathrm{HCV}$ infections. A number of reports have described the potential use of other antiviral ribonucleosides (AVRNs) as anti-viral and anti-cancer agents; however, many of these AVRNs have had adverse toxic effects when administered to patients and did not pass clinical trials or gain FDA approval (Arnold et al., 2012a,b). For example, the AVRN analog BMS986094 developed to treat HCV infection did not pass phase II development after nine patients became hospitalized and one died (Mislak and Anderson, 2015). Utilizing a POLRMT in vitro biochemical system to measure substrate utilization a panel of more than 10 AVRN analogs were investigated that contained moieties found in past and lead anti-HCV non-obligate chain terminators (Arnold et al., 2012a). Nonobligate chain terminators are AVRNs containing a $3^{\prime}-\mathrm{OH}$ yet prevent viral RNA elongation. Except for one analog, all AVRN triphosphates (AVRNts) investigated were readily utilized by POLRMT as off-target substrates and five analogs were strong non-obligate chain terminators of POLRMT RNA elongation. Utilizing the human hepatoma cell line, Huh-7, the panel of AVRNs were metabolized to active triphosphates, presumably by intracellular kinases, and the levels of the triphosphate forms varied from less than $0.15 \mu \mathrm{M}$ to $3.5 \mathrm{mM}$. Cellular evidence for
AVRNs being used as substrates by POLRMT was demonstrated using Huh-7 cells pre-treated for $24 \mathrm{~h}$ with EtBr to suppress mitochondrial transcription then cells were exposed to AVRNs for 1,2, and 3 days. Mitochondrial transcription was impaired in cells exposed to 2'-C-methyladenosine, 6-methylpurine-riboside, and $4^{\prime}$-azidocytidine. This study demonstrated that toxic effects of AVRNs might result from inhibition of the mitochondrial transcription machinery and mtDNA gene expression (Arnold et al., 2012a). Due to the close coupling of mitochondrial transcription and mtDNA replication, prolonged exposure to AVRNs might also affect mtDNA maintenance, Figures 1B,C.

\section{OTHER REPORTS OF DRUGS WITH OFF-TARGET EFFECTS ON mIDNA MAINTENANCE}

Four human cellular topoisomerases localize to mitochondria: TOP $1 \mathrm{mt}$, TOP $2 \alpha$, TOP2 $\beta$, and a TOP $\alpha \alpha$ long isoform (Zhang H. et al., 2014; Pommier et al., 2016). Tamoxifen a drug used to prevent breast cancer, tacrine a drug used to treat Alzheimer's disease, and a fluoroquinolone broad-spectrum antibiotic, have all been hypothesized to have off-target effects on mitochondrial topoisomerases (Lawrence et al., 1996; Mansouri et al., 2003; Larosche et al., 2007; Nadanaciva et al., 2010; Begriche et al., 2011). Mice separately treated for 28 days with tamoxifen and tacrine displayed mtDNA depletion and both of these drugs were demonstrated to inhibit in vitro topoisomerasemediated plasmid DNA relaxation (Mansouri et al., 2003; Larosche et al., 2007). The fluoroquinolone ciprofloxacin, an inhibitor of bacterial type II topoisomerase DNA gyrase, was reported to induce double-strand mtDNA breaks when mouse L1210 cells were exposed to various concentrations of the drug (Lawrence et al., 1996). The pyrrole alkaloid lamellarin D and the chemotherapy drug doxorubicin have both been shown to poison mitochondrial and nuclear topoisomerases (Pommier et al., 2016).

Menadione (vitamin K3, VK3) has been demonstrated to inhibit the growth of human cancer cell lines derived from various tissues and induces an increase in ROS leading to apoptosis. In an in vitro biochemical assay VK3 selectively inhibited Pol $\gamma$ DNA polymerase and RT activities but did not inhibit the activity of other DNA polymerases tested including Pols $\alpha, \beta, \delta, \varepsilon$, eta $(\eta)$, iota $(\iota)$, kappa $(\kappa)$, and lambda $(\lambda)$. The authors proposed that suppression of mtDNA replication and repair could trigger ROS production leading to apoptotic cell death (Sasaki et al., 2008). Although the neurotoxicant 1-methyl-4-phenylpyridinium ion (MPP+) does not directly inhibit the catalytic activity of Pol $\gamma, \mathrm{MPP}+$ was reported to cause mtDNA depletion by destabilizing the mtDNA displacement-loop, a mtDNA replication intermediate, thereby inhibiting mitochondrial genome replication (Umeda et al., 2000). Acetaminophen (APAP or paracetamol) is a commonly used over the counter drug used for fever and pain relief. Mice treated with $300 \mathrm{mg} / \mathrm{kg}$ of acetaminophen had mtDNA depletion as quantitated using a slot blot hybridization technique (Cover et al., 2005). The depletion is likely due to mtDNA 
stand breaks caused by the production of ROS, reactive nitrogen species (RNS), and other reactive metabolites followed by rapid degradation of damaged mtDNA by endogenous mitochondrial endonucleases (Begriche et al., 2011). Troglitazone is an antiinflammatory and anti-diabetic drug that was withdrawn from the market due to serious hepatotoxicity. Primary human hepatocytes exposed to troglitazone had increased mtDNA depletion, decreased ATP production, and decreased cellular viability (Rachek et al., 2009). ROS and oxidative stress were hypothesized to be the source of mtDNA depletion causing mtDNA strand breaks and cytotoxicity and treatment with $\mathrm{N}$ acetyl cysteine (NAC), a known ROS scavenger, reduced the troglitazone-induced cytotoxicity. Cisplatin is a platinum-based FDA-approved chemotherapeutic known to damage nDNA by forming inter-strand crosslinks. Patients treated with platinumbased compounds often display peripheral neuropathy, which may result from damage to dorsal root ganglion neuronal mtDNA (Cline, 2012). In vitro work has demonstrated cisplatin or oxaliplatin block Pol $\gamma$ DNA synthesis. Furthermore, cisplatin has been demonstrated to inhibit rat neuronal mtDNA replication and mitochondrial transcription (Vaisman et al., 1999; Podratz et al., 2011; Cline, 2012).

\section{TARGETING MIDNA MAINTENANCE TO KILL CANCER CELLS}

Cancer cells display uninhibited DNA replication; therefore, DNA polymerases and DNA repair proteins have been exploited as therapeutic targets to combat certain types of cancer (Lange et al., 2011; Somasagara et al., 2017). NRTI-sensitive mitochondrial DNA polymerases afford a unique opportunity to target cancer cell mitochondria as certain cancers have an increased reliance on OXPHOS and nDNA polymerases are less sensitive to NRTI inhibition (Martin et al., 1994; Liyanage et al., 2017). In a study comparing normal hematopoietic cells to a panel of 542 primary acute myeloid leukemia (AML) samples, it was recently discovered that $55 \%$ of the AML samples had increased mtDNA biosynthesis gene expression. Upregulated genes included POLG, POLG2, POLRMT, Twinkle, TFAM, SSBP1, DGUOK, TK2, nucleotide transporters (SLC25A33, $S L C 25 A 36$, and SLC29A3) and nucleoside kinases (CMPK1 and NME1-NME2). When treated with ddC AML cells preferentially activated the analog and blocked mtDNA replication and OXPHOS in comparison to hematopoietic cells. Cytotoxicity was preferentially activated in NRTI-treated AML cells and an AML animal model treated with low doses of ddC (35 and $75 \mathrm{mg} / \mathrm{kg} /$ day over 11 days) resulted in decreased mtDNA, decreased mtDNA-encoded cytochrome oxidase subunit 2 (COX II), and induced tumor regression without apparent toxicity (Liyanage et al., 2017).

Targeting mtDNA maintenance has also been exploited to treat cancer cell lines with a mitochondrial-targeted cisplatin (Marrache et al., 2014). Nucleotide excision repair (NER) machinery repairs cisplatin-nDNA adducts; however, mitochondria lack NER machinery to deal with this type of damage. Most cancer cells have an increased mitochondrial membrane potential relative to non-cancer cells and triphenylphosphonium (TPP) cations are targeted to mitochondria due to their size, lipophilic properties, and delocalized positive charge. An engineered TPP-tagged cisplatin, Platin-M, caused increased cytotoxicity relative to cisplatin only treatment in several cancer cell models: cisplatin-resistant A2780/CP70 ovarian cancer, prostate cancer PC3 (inherently resistant to cisplatin therapy), and SH-SY5Y neuroblastoma cells. Furthermore, encapsulating Platin-M into specialized nanoparticles enhanced cytotoxicity. SH-SY5Y cells treated with Platin-M and Platin-M encapsulated in nanoparticles were annexin V-positive and propidium iodide-negative, indicative of early apoptosis. Treatment with both Platin-M and Platin-M encapsulated in nanoparticles weakened mitochondrial citrate synthase activity and diminished bioenergetic parameters: spare respiratory capacity, coupling efficiency, and basal respiration. PC3 cells treated separately with cisplatin, Platin-M, and Platin-M encapsulated inside of nanoparticles were subjected to subcellular fractionation then platinum concentrations in various fractions were quantified. Cells treated with Platin-M and Platin-M encapsulated in nanoparticles, contained platinummtDNA adducts while cells treated with cisplatin contained mostly platinum-nDNA adducts. These findings support that cisplatin is likely released from Platin-M within mitochondria then binds to mtDNA and inhibits replication.

\section{CONCLUSIONS}

Evaluation of antibiotic and antiviral mitochondrial exposures using biochemistry and human cell line and animal models is an important consideration for determining drug toxicity because the complex mitochondrial network harbors multiple copies of OXPHOS complexes and mtDNA that may cause a slow response to these agents. Chronic exposures to drugs may result in long-term mtDNA and OXPHOS depletion. NRTIs may have tissue-specific toxicities such as skeletal- and cardiomyopathies, peripheral neuropathy, and others (Table 2 and Lewis et al., 2001). Side effects may limit NRTI use in some individuals, cause organ failure and death in others or may only result in minor discomfort (Koczor and Lewis, 2010). Gene variations (like those seen in POLG encoding p140 R964C, R953C, and E1143D/G) may exacerbate mitochondrial diseaselike phenotypes in HIV-infected patients treated with NRTIs. Also, valproic acid has been demonstrated to induce liver failure in autosomal recessive POLG disease but may not be as toxic in autosomal dominant disease. However, due to the potential for valproic acid to cause death by liver toxicity experts recommend avoiding this drug (Saneto and Naviaux, 2010). $P O L G$ is a highly polymorphic gene and the association between disease-causing and non-disease causing substitutions are often unclear and dependent on other complex factors. How other drugs or environmental factors interact with various genetic variant backgrounds (so-called ecogenetic single nucleotide variants, ESNVs) and contribute to mitochondrial disease manifestation is poorly understood (Saneto and Naviaux, 2010; Zolkipli-Cunningham and Falk, 2017). Do ESNVs predispose individuals to mitochondrial dysfunction via pharmacological 
or environmental toxicants while individuals harboring other polymorphism remain resistant? ESNV-environment interaction is an important area for future mitochondrial disease and mtDNA maintenance research. Evidence suggests mitochondria are targets of environmental toxicants that disrupt mtDNA maintenance and chemical exposures may cause increased and decreased mtDNA copy number. At low doses, oxidative stress stimulates mtDNA replication but at high doses mtDNA depletion. Polycyclic aromatic hydrocarbons cause more damage to mtDNA than to nDNA and a compilation of studies comparing nDNA to mtDNA damage following chemical exposure has been reviewed (Meyer et al., 2013).

Evidence suggests five DNA polymerases localize to human cell mitochondria: $\operatorname{Pol} \gamma, \operatorname{Pol} \beta, \operatorname{PrimPol}, \operatorname{Pol} \theta$, and $\operatorname{Pol} \zeta$. In vitro biochemistry measuring substrate binding and incorporation lends strong support to Pol $\gamma, \operatorname{Pol} \beta$, and PrimPol being offtargets for nucleotide analogs (Pelletier et al., 1994; Szymanski et al., 2015). Additionally, the Pol $\theta$ carboxyl-terminal polymerase domain has been crystallized in a translesion DNA synthesis mode inserting ddAppp opposite a template abasic site (Zahn et al., 2015). Comparative investigations of mtDNA polymerase enzyme kinetics and determination of crystal structures with and without lesions will assist in our understanding of the spectrum of mtDNA polymerase toxicity. The overarching goal is that these structure-function studies will assist with designing novel antiviral analogs with higher specificity to viral polymerases and less mitochondrial off-target effects. In mice, mitochondrial $\operatorname{Pol} \beta$ was undetectable in heart, liver, and muscle but was present in organelles obtained from brain and kidney (Sykora et al., 2017). Potential questions for future research include: (1) How are the other newly identified mtDNA polymerases

\section{REFERENCES}

Alexeyev, M., Shokolenko, I., Wilson, G., and LeDoux, S. (2013). The maintenance of mitochondrial DNA integrity-critical analysis and update. Cold Spring Harb. Perspect. Biol. 5:a012641. doi: 10.1101/cshperspect.a012641

Andersson, S. G., Zomorodipour, A., Andersson, J. O., Sicheritz-Pontén, T., Alsmark, U. C., Podowski, R. M., et al. (1998). The genome sequence of Rickettsia prowazekii and the origin of mitochondria. Nature 396, 133-140. doi: $10.1038 / 24094$

Arana, M. E., Seki, M., Wood, R. D., Rogozin, I. B., and Kunkel, T. A. (2008). Lowfidelity DNA synthesis by human DNA polymerase theta. Nucleic Acids Res. 36, 3847-3856. doi: 10.1093/nar/gkn310

Archer, S. L. (2013). Mitochondrial dynamics-mitochondrial fission and fusion in human diseases. N. Engl. J. Med. 369, 2236-2251. doi: 10.1056/NEJMra12 15233

Arnaudo, E., Dalakas, M., Shanske, S., Moraes, C. T., DiMauro, S., and Schon, E. A. (1991). Depletion of muscle mitochondrial DNA in AIDS patients with zidovudine- induced myopathy. Lancet 337, 508-510. doi: 10.1016/0140-6736(91)91294-5

Arnold, J. J., Sharma, S. D., Feng, J. Y., Ray, A. S., Smidansky, E. D., Kireeva, M. L., et al. (2012a). Sensitivity of mitochondrial transcription and resistance of RNA polymerase II dependent nuclear transcription to antiviral ribonucleosides. PLoS Pathog. 8:e1003030. doi: 10.1371/journal.ppat.1003030

Arnold, J. J., Smidansky, E. D., Moustafa, I. M., and Cameron, C. E. (2012b). Human mitochondrial RNA polymerase: structure-function, mechanism and inhibition. Biochim. Biophys. Acta 1819, 948-960. doi: 10.1016/j.bbagrm.2012.04.002 distributed among human organs and tissues and do they associate with other components of the mtDNA repair or replication machinery? Knowledge of the distribution of mtDNA polymerases within human tissues may assist with the prediction of tissue-specific toxicant effects. (2) Could knowledge of mtDNA polymerases within different tissues be exploited to treat certain types of cancers with NRTIs? (3) What analogs and toxicants are incorporated by the newly identified mtDNA polymerases? And (4) Do ESNVs exist in any other genes of interest required for mtDNA maintenance? Current next-generation sequencing technologies and continued research utilizing in vitro biochemistry and model systems such as human cell lines and mice will be essential to answer these questions and will be necessary for future investigations of mitochondrial dysfunction and disease.

\section{AUTHOR CONTRIBUTIONS}

The author confirms being the sole contributor of this work and approved it for publication.

\section{FUNDING}

This research was supported by an NIH Pathway to Independence Award to MY (5R00ES022638-03).

\section{ACKNOWLEDGMENTS}

I would like to thank Carolyn Young for critically reading and editing this manuscript and the two reviewers for their critical assessment of this work.
Ashley, N., Harris, D., and Poulton, J. (2005). Detection of mitochondrial DNA depletion in living human cells using PicoGreen staining. Exp. Cell Res. 303, 432-446. doi: 10.1016/j.yexcr.2004.10.013

Bailey, C. M., Kasiviswanathan, R., Copeland, W. C., and Anderson, K. S. (2009). R964C mutation of DNA polymerase gamma imparts increased stavudine toxicity by decreasing nucleoside analog discrimination and impairing polymerase activity. Antimicrob. Agents Chemother. 53, 2610-2612. doi: 10.1128/AAC.01659-08

Bebenek, K., and Kunkel, T. A. (2004). Functions of DNA polymerases. Adv. Protein Chem. 69, 137-165. doi: 10.1016/S0065-3233(04)69 005-X

Begriche, K., Massart, J., Robin, M. A., Borgne-Sanchez, A., and Fromenty, B. (2011). Drug-induced toxicity on mitochondria and lipid metabolism: mechanistic diversity and deleterious consequences for the liver. J. Hepatol. 54, 773-794. doi: 10.1016/j.jhep.2010.11.006

Berglund, A. K., Navarrete, C., Engqvist, M. K., Hoberg, E., Szilagyi, Z., Taylor, R., et al. (2017). Nucleotide pools dictate the identity and frequency of ribonucleotide incorporation in mitochondrial DNA. PLoS Genet. 13:e1006628. doi: 10.1371/journal.pgen.1006628

Besse, A., Wu, P., Bruni, F., Donti, T., Graham, B. H., Craigen, W. J., et al. (2015). The GABA transaminase, ABAT, is essential for mitochondrial nucleoside metabolism. Cell Metab. 21, 417-427. doi: 10.1016/j.cmet.2015. 02.008

Birkus, G., Hitchcock, M. J., and Cihlar, T. (2002). Assessment of mitochondrial toxicity in human cells treated with tenofovir: comparison with other nucleoside reverse transcriptase inhibitors. Antimicrob. Agents Chemother. 46, 716-723. doi: 10.1128/AAC.46.3.716-723.2002 
Blanc, H., Adams, C. W., and Wallace, D. C. (1981). Different nucleotide changes in the large rRNA gene of the mitochondrial DNA confer chloramphenicol resistance on two human cell lines. Nucleic Acids Res. 9, 5785-5795. doi: 10.1093/nar/9.21.5785

Bogenhagen, D. F., Rousseau, D., and Burke, S. (2008). The layered structure of human mitochondrial DNA nucleoids. J. Biol. Chem. 283, 3665-3675. doi: 10.1074/jbc.M708444200

Brown, J. A., Pack, L. R., Fowler, J. D., and Suo, Z. (2011). Pre-steady-state kinetic analysis of the incorporation of anti-HIV nucleotide analogs catalyzed by human X- and Y-family DNA polymerases. Antimicrob. Agents Chemother. 55, 276-283. doi: 10.1128/AAC.01229-10

Brown, J. A., Pack, L. R., Fowler, J. D., and Suo, Z. (2012). Presteady state kinetic investigation of the incorporation of anti-hepatitis $B$ nucleotide analogues catalyzed by noncanonical human DNA polymerases. Chem. Res. Toxicol. 25, 225-233. doi: $10.1021 / \mathrm{tx} 200458 \mathrm{~s}$

Brown, T. A., Tkachuk, A. N., Shtengel, G., Kopek, B. G., Bogenhagen, D. F., Hess, H. F., et al. (2011). Superresolution fluorescence imaging of mitochondrial nucleoids reveals their spatial range, limits, and membrane interaction. Mol. Cell. Biol. 31, 4994-5010. doi: 10.1128/MCB.05694-11

Brown, T. A., and Clayton, D. A. (2002). Release of replication termination controls mitochondrial DNA copy number after depletion with $2^{\prime}, 3^{\prime}$-dideoxycytidine. Nucleic Acids Res. 30, 2004-2010. doi: 10.1093/nar/30.9.2004

Calvo, S. E., Clauser, K. R., and Mootha, V. K. (2016). MitoCarta2.0: an updated inventory of mammalian mitochondrial proteins. Nucleic Acids Res. 44, D1251-D1257. doi: 10.1093/nar/gkv1003

Cerritelli, S. M., Frolova, E. G., Feng, C., Grinberg, A., Love, P. E., and Crouch, R. (2003). Failure to produce mitochondrial DNA results in embryonic lethality in Rnaseh1 null mice. Mol. Cell 11, 807-815. doi: 10.1016/S1097-2765(03)00088-1

Chang, D. D., and Clayton, D. A. (1985). Priming of human mitochondrial DNA replication occurs at the light-strand promoter. Proc. Natl. Acad. Sci. U.S.A. 82, 351-355. doi: 10.1073/pnas.82.2.351

Chiappini, F., Teicher, E., Saffroy, R., Debuire, B., Vittecoq, D., and Lemoine, A. (2009). Relationship between polymerase gamma (POLG) polymorphisms and antiretroviral therapy-induced lipodystrophy in HIV-1 infected patients: a casecontrol study. Curr. HIV Res. 7, 244-253. doi: 10.2174/157016209787581409

Cline, S. D. (2012). Mitochondrial DNA damage and its consequences for mitochondrial gene expression. Biochim. Biophys. Acta 1819, 979-991. doi: $10.1016 /$ j.bbagrm.2012.06.002

Copeland, W. C., and Longley, M. J. (2014). Mitochondrial genome maintenance in health and disease. DNA Rep. 19, 190-198. doi: 10.1016/j.dnarep.2014.03.010

Cover, C., Mansouri, A., Knight, T. R., Bajt, M. L., Lemasters, J. J., Pessayre, D., et al. (2005). Peroxynitrite-induced mitochondrial and endonuclease-mediated nuclear DNA damage in acetaminophen hepatotoxicity. J. Pharmacol. Exp. Ther. 315, 879-887. doi: 10.1124/jpet.105.088898

Dalakas, M. C., Illa, I., Pezeshkpour, G. H., Laukaitis, J. P., Cohen, B., and Griffin, J. L. (1990). Mitochondrial myopathy caused by long-term zidovudine therapy. N. Engl. J. Med. 322, 1098-1105. doi: 10.1056/NEJM199004193221602

Dalakas, M. C., Semino-Mora, C., and Leon-Monzon, M. (2001). Mitochondrial alterations with mitochondrial DNA depletion in the nerves of AIDS patients with peripheral neuropathy induced by $2^{\prime} 3^{\prime}$-dideoxycytidine (ddC). Lab. Invest. 81, 1537-1544. doi: 10.1038/labinvest.3780367

Esposito, G., Godindagger, I., Klein, U., Yaspo, M. L., Cumano, A., and Rajewsky, K. (2000). Disruption of the Rev3l-encoded catalytic subunit of polymerase zeta in mice results in early embryonic lethality. Curr. Biol. 10, 1221-1224. doi: 10.1016/S0960-9822(00)00726-0

Feng, J. Y., Johnson, A. A., Johnson, K. A., and Anderson, K. S. (2001). Insights into the molecular mechanism of mitochondrial toxicity by AIDS drugs. J. Biol. Chem. 276, 23832-23837. doi: 10.1074/jbc.M101156200

Fernández-Moreno, M., Hermida-Gómez, T., Gallardo, M. E., DalmaoFernández, A., Rego-Pérez, I., Garesse, R., et al. (2016). Generating Rho-0 cells using mesenchymal stem cell lines. PLoS ONE 11:e0164199. doi: 10.1371/journal.pone.0164199

García-Gómez, S., Reyes, A., Martínez-Jiménez, M. I., Chocrón, E. S., Mourón, S., Terrados, G., et al. (2013). PrimPol, an archaic primase/polymerase operating in human cells. Mol. Cell 52, 541-553. doi: 10.1016/j.molcel.2013.09.025

Gentry, A. C., Juul, S., Veigaard, C., Knudsen, B. R., and Osheroff, N. (2011). The geometry of DNA supercoils modulates the DNA cleavage activity of human topoisomerase I. Nucleic Acids Res. 39, 1014-1022. doi: 10.1093/nar/gkq822
Gray, M. W. (2017). Lynn Margulis and the endosymbiont hypothesis: 50 years later. Mol. Biol. Cell 28, 1285-1287. doi: 10.1091/mbc.E16-07-0509

Graziewicz, M. A., Longley, M. J., and Copeland, W. C. (2006). DNA polymerase gamma in mitochondrial DNA replication and repair. Chem. Rev. 106, 383-405. doi: $10.1021 /$ cr040463d

Hance, N., Ekstrand, M. I., and Trifunovic, A. (2005). Mitochondrial DNA polymerase gamma is essential for mammalian embryogenesis. Hum. Mol. Genet. 14, 1775-1783. doi: $10.1093 / \mathrm{hmg} / \mathrm{ddil} 184$

Hensen, F., Cansiz, S., Gerhold, J. M., and Spelbrink, J. N. (2014). To be or not to be a nucleoid protein: a comparison of mass-spectrometry based approaches in the identification of potential mtDNA-nucleoid associated proteins. Biochimie 100, 219-226. doi: 10.1016/j.biochi.2013.09.017

Holmes, J. B., Akman, G., Wood, S. R., Sakhuja, K., Cerritelli, S. M., Moss, C., et al. (2015). Primer retention owing to the absence of RNase H1 is catastrophic for mitochondrial DNA replication. Proc. Natl. Acad. Sci. U.S.A. 112, 9334-9339. doi: 10.1073/pnas.1503653112

Humble, M. M., Young, M. J., Foley, J. F., Pandiri, A. R., Travlos, G. S., and Copeland, W. C. (2013). Polg2 is essential for mammalian embryogenesis and is required for mtDNA maintenance. Hum. Mol. Genet. 22, 1017-1025. doi: $10.1093 / \mathrm{hmg} / \mathrm{dds} 506$

Iborra, F. J., Kimura, H., and Cook, P. R. (2004). The functional organization of mitochondrial genomes in human cells. BMC Biol. 2:9. doi: 10.1186/1741-7007-2-9

Iyengar, B., Luo, N., Farr, C. L., Kaguni, L. S., and Campos, A. R. (2002). The accessory subunit of DNA polymerase gamma is essential for mitochondrial DNA maintenance and development in Drosophila melanogaster. Proc. Natl. Acad. Sci. U.S.A. 99, 4483-4488. doi: 10.1073/pnas.072664899

Jemt, E., Persson, Ö., Shi, Y., Mehmedovic, M., Uhler, J. P., Dávila López, M., et al. (2015). Regulation of DNA replication at the end of the mitochondrial D-loop involves the helicase TWINKLE and a conserved sequence element. Nucleic Acids Res. 43, 9262-9275. doi: 10.1093/nar/gkv804

Johnson, A. A., Ray, A. S., Hanes, J., Suo, Z., Colacino, J. M., Anderson, K. S., et al. (2001). Toxicity of antiviral nucleoside analogs and the human mitochondrial DNA polymerase. J. Biol. Chem. 276, 40847-40857. doi: 10.1074/jbc.M106743200

Kaguni, L. S. (2004). DNA polymerase gamma, the mitochondrial replicase. Annu. Rev. Biochem. 73, 293-320. doi: 10.1146/annurev.biochem.72.121801. 161455

Kalifa, L., Beutner, G., Phadnis, N., Sheu, S. S., and Sia, E. A. (2009). Evidence for a role of FEN1 in maintaining mitochondrial DNA integrity. DNA Rep. 8, 1242-1249. doi: 10.1016/j.dnarep.2009.07.008

Kasamatsu, H., and Vinograd, J. (1974). Replication of circular DNA in eukaryotic cells. Аnnu. Rev. Biochem. 43, 695-719. doi: 10.1146/annurev.bi.43.070174.003403

Kearsey, S. E., and Craig, I. W. (1981). Altered ribosomal RNA genes in mitochondria from mammalian cells with chloramphenicol resistance. Nature 290, 607-608. doi: 10.1038/290607a0

Keen, B. A., Bailey, L. J., Jozwiakowski, S. K., and Doherty, A. J. (2014). Human PrimPol mutation associated with high myopia has a DNA replication defect. Nucleic Acids Res. 42, 12102-12111. doi: 10.1093/nar/gku879

King, M. P., and Attardi, G. (1996). Isolation of human cell lines lacking mitochondrial DNA. Meth. Enzymol. 264, 304-313. doi: 10.1016/S0076-6879(96)64029-4

Koczor, C. A., and Lewis, W. (2010). Nucleoside reverse transcriptase inhibitor toxicity and mitochondrial DNA. Expert Opin. Drug Metab. Toxicol. 6, 1493-1504. doi: 10.1517/17425255.2010.526602

Kornblum, C., Nicholls, T. J., Haack, T. B., Schöler, S., Peeva, V., Danhauser, K., et al. (2013). Loss-of-function mutations in MGME1 impair mtDNA replication and cause multisystemic mitochondrial disease. Nat. Genet. 45, 214-219. doi: 10.1038/ng.2501

Krasich, R., and Copeland, W. C. (2017). DNA polymerases in the mitochondria: a critical review of the evidence. Front. Biosci. 22, 692-709. doi: 10.2741/4510

Lange, S. S., Takata, K., and Wood, R. D. (2011). DNA polymerases and cancer. Nat. Rev. Cancer 11, 96-110. doi: 10.1038/nrc2998

Larosche, I., Lettéron, P., Fromenty, B., Vadrot, N., Abbey-Toby, A., Feldmann, G., et al. (2007). Tamoxifen inhibits topoisomerases, depletes mitochondrial DNA, and triggers steatosis in mouse liver. J. Pharmacol. Exp. Ther. 321, 526-535. doi: $10.1124 /$ jpet.106.114546 
Lawrence, J. W., Claire, D. C., Weissig, V., and Rowe, T. C. (1996). Delayed cytotoxicity and cleavage of mitochondrial DNA in ciprofloxacin-treated mammalian cells. Mol. Pharmacol. 50, 1178-1188.

Lee, S.-K., Zhao, M.-H., Zheng, Z., Kwon, J.-W., Liang, S., Kim, S.-H., et al. (2015). Polymerase subunit gamma 2 affects porcine oocyte maturation and subsequent embryonic development. Theriogenology 83, 121-30. doi: 10.1016/j.theriogenology.2014.08.019

Lee, Y. S., Gregory, M. T., and Yang, W. (2014). Human Pol $\zeta$ purified with accessory subunits is active in translesion DNA synthesis and complements Pol $\eta$ in cisplatin bypass. Proc. Natl. Acad. Sci. U.S.A. 111, 2954-2959. doi: 10.1073/pnas.1324001111

Lewis, W., Papoian, T., Gonzalez, B., Louie, H., Kelly, D. P., Payne, R. M., et al. (1991). Mitochondrial ultrastructural and molecular changes induced by zidovudine in rat hearts. Lab. Invest. 65, 228-236.

Lewis, W., Levine, E. S., Griniuviene, B., Tankersley, K. O., Colacino, J. M., Sommadossi, J. P., et al. (1996). Fialuridine and its metabolites inhibit DNA polymerase gamma at sites of multiple adjacent analog incorporation, decrease mtDNA abundance, and cause mitochondrial structural defects in cultured hepatoblasts. Proc. Natl. Acad. Sci. U.S.A. 93, 3592-3597. doi: 10.1073/pnas.93.8.3592

Lewis, W., Copeland, W. C., and Day, B. (2001). Mitochondrial DNA depletion, oxidative stress and mutation: mechanisms of nucleoside reverse transcriptase inhibitor toxicity. Lab. Invest. 81, 777-790. doi: 10.1038/labinvest.3780288

Li, M., Mislak, A. C., Foli, Y., Agbosu, E., Bose, V., Bhandari, S., et al. (2016). The DNA polymerase gamma R953C mutant is associated with antiretroviral therapy-induced mitochondrial toxicity. Antimicrob. Agents Chemother. 60, 5608-5611. doi: 10.1128/AAC.00976-16

Lim, S. E., and Copeland, W. C. (2001). Differential incorporation and removal of antiviral deoxynucleotides by human DNA polymerase gamma. J. Biol. Chem. 276, 23616-23623. doi: 10.1074/jbc.M101114200

Lim, S. E., Longley, M. J., and Copeland, W. C. (1999). The mitochondrial p55 accessory subunit of human DNA polymerase gamma enhances DNA binding, promotes processive DNA synthesis, and confers $\mathrm{N}$-ethylmaleimide resistance. J. Biol. Chem. 274, 38197-38203. doi: 10.1074/jbc.274.53.38197

Lim, S. E., Ponamarev, M. V., Longley, M. J., and Copeland, W. C. (2003). Structural Determinants in human DNA polymerase gamma account for mitochondrial toxicity from nucleoside analogs. J. Mol. Biol. 329, 45-57. doi: 10.1016/S0022-2836(03)00405-4

Liyanage, S. U., Hurren, R., Voisin, V., Bridon, G., Wang, X., Xu, C., et al. (2017). Leveraging increased cytoplasmic nucleoside kinase activity to target mtDNA and oxidative phosphorylation in AML. Blood 129, 2657-2666. doi: 10.1182/blood-2016-10-741207

Lodeiro, M. F., Uchida, A., Bestwick, M., Moustafa, I. M., Arnold, J. J., Shadel, G. S., et al. (2012). Transcription from the second heavy-strand promoter of human mtDNA is repressed by transcription factor A in vitro. Proc. Natl. Acad. Sci. U.S.A. 109, 6513-6518. doi: 10.1073/pnas.1118710109

Longley, M. J., Humble, M. M., Sharief, F. S., and Copeland, W. C. (2010). Disease variants of the human mitochondrial DNA helicase encoded by C10orf2 differentially alter protein stability, nucleotide hydrolysis and helicase activity. J. Biol. Chem. 285, 29690-29702. doi: 10.1074/jbc.M110.151795

Longley, M. J., Prasad, R., Srivastava, D. K., Wilson, S. H., and Copeland, W. C. (1998). Identification of 5' -deoxyribose phosphate lyase activity in human DNA polymerase gamma and its role in mitochondrial base excision repair in vitro. Proc. Natl. Acad. Sci. U.S.A. 95, 12244-12248. doi: 10.1073/pnas.95.21.12244

Lopez, M. F., Kristal, B. S., Chernokalskaya, E., Lazarev, A., Shestopalov, A. I., Bogdanova, A., et al. (2000). High-throughput profiling of the mitochondrial proteome using affinity fractionation and automation. Electrophoresis $\quad 21, \quad 3427-3440 . \quad$ doi: $\quad 10.1002 / 1522-2683(20001001)$ 21:16<3427::AID-ELPS3427>3.0.CO;2-L

Mansouri, A., Haouzi, D., Descatoire, V., Demeilliers, C., Sutton, A., Vadrot, N., et al. (2003). Tacrine inhibits topoisomerases and DNA synthesis to cause mitochondrial DNA depletion and apoptosis in mouse liver. Hepatology 38, 715-725. doi: 10.1053/jhep.2003.50353

Marrache, S., Pathak, R. K., and Dhar, S. (2014). Detouring of cisplatin to access mitochondrial genome for overcoming resistance. Proc. Natl. Acad. Sci. U.S.A. 111, 10444-10449. doi: 10.1073/pnas.1405244111

Martin, J. L., Brown, C. E., Matthews-Davis, N., and Reardon, J. E. (1994). Effects of antiviral nucleoside analogs on human DNA polymerases and mitochondrial DNA synthesis. Antimicrob. Agents Chemother. 38, 2743-2749. doi: 10.1128/AAC.38.12.2743

McKee, E. E., Bentley, A. T., Hatch, M., Gingerich, J., and Susan-Resiga, D. (2004). Phosphorylation of thymidine and AZT in heart mitochondria: elucidation of a novel mechanism of AZT cardiotoxicity. Cardiovasc. Toxicol. 4, 155-167. doi: 10.1385/CT:4:2:155

McKenzie, R., Fried, M. W., Sallie, R., Conjeevaram, H., Di Bisceglie, A. M., Park, Y., et al. (1995). Hepatic failure and lactic acidosis due to fialuridine (FIAU), an investigational nucleoside analogue for chronic hepatitis B. N. Engl. J. Med. 333, 1099-1105. doi: 10.1056/NEJM1995102633 31702

Medina, D. J., Tsai, C. H., Hsiung, G. D., and Cheng, Y. C. (1994). Comparison of mitochondrial morphology, mitochondrial DNA content, and cell viability in cultured cells treated with three anti-human immunodeficiency virus dideoxynucleosides. Antimicrob. Agents Chemother. 38, 1824-1828. doi: 10.1128/AAC.38.8.1824

Meyer, J. N., Leung, M. C., Rooney, J. P., Sendoel, A., Hengartner, M. O., Kisby, G. E., et al. (2013). Mitochondria as a target of environmental toxicants. Toxicol. Sci. 134, 1-17. doi: 10.1093/toxsci/kft102

Miller, F. J., Rosenfeldt, F. L., Zhang, C., Linnane, A. W., and Nagley, P. (2003). Precise determination of mitochondrial DNA copy number in human skeletal and cardiac muscle by a PCR-based assay: lack of change of copy number with age. Nucleic Acids Res. 31:e61. doi: 10.1093/nar/gng060

Mislak, A. C., and Anderson, K. S. (2015). Insights into the molecular mechanism of polymerization and nucleoside reverse transcriptase inhibitor incorporation by human PrimPol. Antimicrob. Agents Chemother. 60, 561-569. doi: 10.1128/AAC.02270-15

Murakami, E., Feng, J. Y., Lee, H., Hanes, J., Johnson, K. A., and Anderson, K. S. (2003). Characterization of novel reverse transcriptase and other RNAassociated catalytic activities by human DNA polymerase gamma: importance in mitochondrial DNA replication. J. Biol. Chem. 278, 36403-36409. doi: $10.1074 /$ jbc.M306236200

Nadanaciva, S., Dillman, K., Gebhard, D. F., Shrikhande, A., and Will, Y. (2010). High-content screening for compounds that affect mtDNAencoded protein levels in eukaryotic cells. J. Biomol. Screen. 15, 937-948. doi: $10.1177 / 1087057110373547$

Ngo, H. B., Lovely, G. A., Phillips, R., and Chan, D. C. (2014). Distinct structural features of TFAM drive mitochondrial DNA packaging versus transcriptional activation. Nat. Commun. 5:3077. doi: 10.1038/ncomms4077

Nolan, D., and Mallal, S. (2004). Complications associated with NRTI therapy: update on clinical features and possible pathogenic mechanisms. Antivir. Ther. 9, 849-863.

Oliver, N. A., and Wallace, D. C. (1982). Assignment of two mitochondrially synthesized polypeptides to human mitochondrial DNA and their use in the study of intracellular mitochondrial interaction. Mol. Cell. Biol. 2, 30-41. doi: 10.1128/MCB.2.1.30

Park, C. B., and Larsson, N. G. (2011). Mitochondrial DNA mutations in disease and aging. J. Cell Biol. 193, 809-818. doi: 10.1083/jcb.201010024

Pau, A. K., and George, J. M. (2014). Antiretroviral therapy: current drugs. Infect. Dis. Clin. North Am. 28, 371-402. doi: 10.1016/j.idc.2014.06.001

Pelletier, H., Sawaya, M. R., Kumar, A., Wilson, S. H., and Kraut, J. (1994). Structures of ternary complexes of rat DNA polymerase beta, a DNA template-primer, and ddCTP. Science 264, 1891-1903. doi: 10.1126/science.75 16580

Pinto, M., and Moraes, C. T. (2014). Mitochondrial genome changes and neurodegenerative diseases. Biochim. Biophys. Acta 1842, 1198-1207. doi: 10.1016/j.bbadis.2013.11.012

Podratz, J. L., Knight, A. M., Ta, L. E., Staff, N. P., Gass, J. M., Genelin, K., et al. (2011). Cisplatin induced mitochondrial DNA damage in dorsal root ganglion neurons. Neurobiol. Dis. 41, 661-668. doi: 10.1016/j.nbd.2010. 11.017

Pommier, Y., Sun, Y., Huang, S. N., and Nitiss, J. L. (2016). Roles of eukaryotic topoisomerases in transcription, replication and genomic stability. Nat. Rev. Mol. Cell Biol. 17, 703-721. doi: 10.1038/nrm.2016.111

Rachek, L. I., Yuzefovych, L. V., Ledoux, S. P., Julie, N. L., and Wilson, G. L. (2009). Troglitazone, but not rosiglitazone, damages mitochondrial DNA and induces mitochondrial dysfunction and cell death in human hepatocytes. Toxicol. Appl. Pharmacol. 240, 348-354. doi: 10.1016/j.taap.2009.07.021 
Reyes, A., Melchionda, L., Nasca, A., Carrara, F., Lamantea, E., Zanolini, A., et al. (2015). RNASEH1 mutations impair mtDNA replication and cause adultonset mitochondrial encephalomyopathy. Am. J. Hum. Genet. 97, 186-193. doi: 10.1016/j.ajhg.2015.05.013

Rocher, C., Taanman, J. W., Pierron, D., Faustin, B., Benard, G., Rossignol, R., et al. (2008). Influence of mitochondrial DNA level on cellular energy metabolism: implications for mitochondrial diseases. J. Bioenerg. Biomembr. 40, 59-67. doi: 10.1007/s10863-008-9130-5

Ronchi, D., Di Fonzo, A., Lin, W., Bordoni, A., Liu, C., Fassone, E., et al. (2013). Mutations in DNA2 link progressive myopathy to mitochondrial DNA instability. Am. J. Hum. Genet. 92, 293-300. doi: 10.1016/j.ajhg.2012.12.014

Rouzier, C., Bannwarth, S., Chaussenot, A., Chevrollier, A., Verschueren, A., Bonello-Palot, N., et al. (2012). The MFN2 gene is responsible for mitochondrial DNA instability and optic atrophy 'plus' phenotype. Brain 135, 23-34. doi: 10.1093/brain/awr323

Saneto, R. P., and Naviaux, R. K. (2010). Polymerase gamma disease through the ages. Dev. Disabil. Res. Rev. 16, 163-174. doi: 10.1002/ddrr.105

Santos, J. H., Hunakova, L., Chen, Y., Bortner, C., and Van Houten, B. (2003). Cell sorting experiments link persistent mitochondrial DNA damage with loss of mitochondrial membrane potential and apoptotic cell death. J. Biol. Chem. 278, 1728-1734. doi: 10.1074/jbc.M208752200

Sasaki, R., Suzuki, Y., Yonezawa, Y., Ota, Y., Okamoto, Y., Demizu, Y., et al. (2008). DNA polymerase gamma inhibition by vitamin $\mathrm{K} 3$ induces mitochondriamediated cytotoxicity in human cancer cells. Cancer Sci. 99, 1040-1048. doi: 10.1111/j.1349-7006.2008.00771.x

Scharfe, C., Lu, H. H., Neuenburg, J. K., Allen, E. A., Li, G. C., Klopstock, T., et al. (2009). Mapping gene associations in human mitochondria using clinical disease phenotypes. PLoS Comput. Biol. 5:e1000374. doi: 10.1371/journal.pcbi.1000374

Setzer, B., Schlesier, M., Thomas, A. K., and Walker, U. A. (2005). Mitochondrial toxicity of nucleoside analogues in primary human lymphocytes. Antivir. Ther. $10,327-334$

Shima, N., Munroe, R. J., and Schimenti, J. C. (2004). The mouse genomic instability mutation chaos 1 is an allele of Polq that exhibits genetic interaction with Atm. Mol. Cell. Biol. 24, 10381-10389. doi: 10.1128/MCB.24.23.10381-10389.2004

Shutt, T. E., and Gray, M. W. (2006). Bacteriophage origins of mitochondrial replication and transcription proteins. Trends Genet. 22, 90-95. doi: 10.1016/j.tig.2005.11.007

Shutt, T. E. Lodeiro, M. F., Cotney, J., Cameron, C. E., and Shadel, G. S. (2010). Core human mitochondrial transcription apparatus is a regulated twocomponent system in vitro.Proc. Natl. Acad. Sci. U.S.A. 107, 12133-12138. doi: 10.1073/pnas.0910581107

Singh, B., Li, X., Owens, K. M., Vanniarajan, A., Liang, P., and Singh, K. K. (2015). Human REV3 DNA polymerase zeta localizes to mitochondria and protects the mitochondrial genome. PLoS ONE 10:e0140409. doi: 10.1371/journal.pone.0140409

Somasagara, R. R., Spencer, S. M., Tripathi, K., Clark, D. W., Mani, C., da Silva, L. M., et al. (2017). RAD6 promotes DNA repair and stem cell signaling in ovarian cancer and is a promising therapeutic target to prevent and treat acquired chemoresistance. Oncogene. doi: 10.1038/onc.2017.279. [Epub ahead of print].

Spelbrink, J. N. (2010). Functional organization of mammalian mitochondrial DNA in nucleoids: history, recent developments, and future challenges. IUBMB Life 62, 19-32. doi: 10.1002/iub.282

Stewart, J. B., and Larsson, N. G. (2014). Keeping mtDNA in shape between generations. PLoS Genet. 10:e1004670. doi: 10.1371/journal.pgen.10 04670

Stiles, A. R., Simon, M. T., Stover, A., Eftekharian, S., Khanlou, N., Wang, H. L., et al. (2016). Mutations in TFAM, encoding mitochondrial transcription factor A, cause neonatal liver failure associated with mtDNA depletion. Mol. Genet. Metab. 119, 91-99. doi: 10.1016/j.ymgme.2016.07.001

Sugo, N., Aratani, Y., Nagashima, Y., Kubota, Y., and Koyama, H. (2000). Neonatal lethality with abnormal neurogenesis in mice deficient in DNA polymerase beta. EMBO J. 19, 1397-1404. doi: 10.1093/emboj/19.6.1397

Sykora, P., Kanno, S., Akbari, M., Kulikowicz, T., Baptiste, B. A., Leandro, G. S., et al. (2017). DNA polymerase beta participates in mitochondrial DNA repair. Mol. Cell. Biol. doi: 10.1128/MCB.00237-17. [Epub ahead of print].
Szymanski, M. R., Kuznetsov, V. B., Shumate, C., Meng, Q., Lee, Y. S., Patel, G., et al. (2015). Structural basis for processivity and antiviral drug toxicity in human mitochondrial DNA replicase. EMBO J. 34, 1959-1970. doi: 10.15252/embj.201591520

Tann, A. W., Boldogh, I., Meiss, G., Qian, W., Van Houten, B., Mitra, S., et al. (2011). Apoptosis induced by persistent single-strand breaks in mitochondrial genome: critical role of EXOG (5'-EXO/endonuclease) in their repair. J. Biol. Chem. 286, 31975-31983. doi: 10.1074/jbc.M110.215715

Turnbull, D. M., and Rustin, P. (2016). Genetic and biochemical intricacy shapes mitochondrial cytopathies. Neurobiol. Dis. 92, 55-63. doi: 10.1016/j.nbd.2015.02.003

Tyynismaa, H., Mjosund, K. P., Wanrooij, S., Lappalainen, I., Ylikallio, E., Jalanko, A., et al. (2005). Mutant mitochondrial helicase Twinkle causes multiple mtDNA deletions and a late-onset mitochondrial disease in mice. Proc. Natl. Acad. Sci. U.S.A. 102, 17687-17692. doi: 10.1073/pnas.0505551102

Tyynismaa, H., and Suomalainen, A. (2009). Mouse models of mitochondrial DNA defects and their relevance for human disease. EMBO Rep. 10, 137-143. doi: 10.1038/embor.2008.242

Umeda, S., Muta, T., Ohsato, T., Takamatsu, C., Hamasaki, N., and Kang, D. (2000). The D-loop structure of human mtDNA is destabilized directly by $1-$ methyl-4-phenylpyridinium ion (MPP+), a parkinsonism-causing toxin. Eur. J. Biochem. 267, 200-206. doi: 10.1046/j.1432-1327.2000.00990.x

Vaisman, A., Lim, S. E., Patrick, S. M., Copeland, W. C., Hinkle, D. C., Turchi, J. J., et al. (1999). Effect of DNA polymerases and high mobility group protein 1 on the carrier ligand specificity for translesion synthesis past platinum-DNA adducts. Biochemistry 38, 11026-11039. doi: 10.1021/bi9909187

Van Houten, B., Hunter, S. E., and Meyer, J. N. (2016). Mitochondrial DNA damage induced autophagy, cell death, and disease. Front. Biosci. 21, 42-54. doi: $10.2741 / 4375$

Vázquez-Acevedo, M., Coria, R., González-Astiazarán, A., Medina-Crespo, V., Ridaura-Sanz, C., and González-Halphen, D. (1995). Characterization of a 5025 base pair mitochondrial DNA deletion in Kearns-Sayre syndrome. Biochim. Biophys. Acta 1271, 363-368. doi: 10.1016/0925-4439(95)00062-9

Wallace, D. C. (2005). The mitochondrial genome in human adaptive radiation and disease: on the road to therapeutics and performance enhancement. Gene 354, 169-180. doi: 10.1016/j.gene.2005.05.001

Wallace, D. C., Bunn, C. L., and Eisenstadt, J. M. (1975). Cytoplasmic transfer of chloramphenicol resistance in human tissue culture cells. J. Cell Biol. 67, 174-188. doi: $10.1083 /$ jcb.67.1.174

Wallace, D. C., and Chalkia, D. (2013). Mitochondrial DNA genetics and the heteroplasmy conundrum in evolution and disease. Cold Spring Harb. Perspect. Biol. 5:a021220. doi: 10.1101/cshperspect.a021220

Wanrooij, S., Fusté, J. M., Farge, G., Shi, Y., Gustafsson, C. M., and Falkenberg, M. (2008). Human mitochondrial RNA polymerase primes lagging-strand DNA synthesis in vitro. Proc. Natl. Acad. Sci. U.S.A. 105, 11122-11127. doi: 10.1073/pnas.0805399105

Wisnovsky, S., Jean, S. R., and Kelley, S. O. (2016). Mitochondrial DNA repair and replication proteins revealed by targeted chemical probes. Nat. Chem. Biol. 12, 567-573. doi: 10.1038/nchembio.2102

Yamanaka, H., Gatanaga, H., Kosalaraksa, P., Matsuoka-Aizawa, S., Takahashi, T., Kimura, S., et al. (2007). Novel mutation of human DNA polymerase gamma associated with mitochondrial toxicity induced by anti-HIV treatment. J. Infect. Dis. 195, 1419-1425. doi: 10.1086/513872

Young, M. J., and Copeland, W. C. (2016). Human mitochondrial DNA replication machinery and disease. Curr. Opin. Genet. Dev. 38, 52-62. doi: 10.1016/j.gde.2016.03.005

Young, M. J., Humble, M. M., DeBalsi, K. L., Sun, K. Y., and Copeland, W. C. (2015). POLG2 disease variants: analyses reveal a dominant negative heterodimer, altered mitochondrial localization and impaired respiratory capacity. Hum. Mol. Genet. 24, 5184-5197. doi: 10.1093/hmg/ddv240

Zahn, K. E., Averill, A. M., Aller, P., Wood, R. D., and Doublié, S. (2015). Human DNA polymerase $\theta$ grasps the primer terminus to mediate DNA repair. Nat. Struct. Mol. Biol. 22, 304-311 doi: 10.1038/nsmb.2993

Zhang, H., Zhang, Y. W., Yasukawa, T., Dalla Rosa, I., Khiati, S., and Pommier, Y. (2014). Increased negative supercoiling of mtDNA in TOP1mt knockout mice and presence of topoisomerases IIalpha and IIbeta in vertebrate mitochondria. Nucleic Acids Res. 42, 7259-7267. doi: 10.1093/nar/gku384 
Zhang, Y., Song, F., Gao, Z., Ding, W., Qiao, L., Yang, S., et al. (2014). Long-term exposure of mice to nucleoside analogues disrupts mitochondrial DNA maintenance in cortical neurons. PLoS ONE 9:e85637. doi: 10.1371/journal.pone.0085637

Zhao, F., Wu, J., Xue, A., Su, Y., Wang, X., Lu, X., et al. (2013). Exome sequencing reveals CCDC111 mutation associated with high myopia. Hum. Genet. 132, 913-921. doi: 10.1007/s00439-013-1303-6

Zheng, L., Zhou, M., Guo, Z., Lu, H., Qian, L., Dai, H., et al. (2008). Human DNA2 is a mitochondrial nuclease/helicase for efficient processing of DNA replication and repair intermediates. Mol. Cell 32, 325-336. doi: 10.1016/j.molcel.2008.09.024

Zhu, C., Johansson, M., and Karlsson, A. (2000). Incorporation of nucleoside analogs into nuclear or mitochondrial DNA is determined by the intracellular phosphorylation site. J. Biol. Chem. 275, 26727-26731. doi: 10.1074/jbc.M002304200
Zolkipli-Cunningham, Z., and Falk, M. J. (2017). Clinical effects of chemical exposures on mitochondrial function. Toxicology. 391, 90-99. doi: 10.1016/j. tox.2017.07.009

Conflict of Interest Statement: The author declares that the research was conducted in the absence of any commercial or financial relationships that could be construed as a potential conflict of interest.

Copyright (c) 2017 Young. This is an open-access article distributed under the terms of the Creative Commons Attribution License (CC BY). The use, distribution or reproduction in other forums is permitted, provided the original author(s) or licensor are credited and that the original publication in this journal is cited, in accordance with accepted academic practice. No use, distribution or reproduction is permitted which does not comply with these terms. 